\title{
REVIEW
}

\section{Doped GaSe crystals for laser frequency conversion}

\author{
Jin Guo ${ }^{1,2}$, Ji-Jiang Xie ${ }^{1,2}$, Dian-Jun Li ${ }^{1,2}$, Gui-Long Yang ${ }^{1,2}$, Fei Chen ${ }^{1,2}$, Chun-Rui Wang ${ }^{1,2}$, Lai-Ming Zhang ${ }^{1}$, \\ Yury M Andreev ${ }^{3,4}$, Konstantin A Kokh ${ }^{5,6}$, Gregory V Lanskii ${ }^{3,4}$ and Valery A Svetlichnyi ${ }^{4}$
}

In this review, we introduce the current state of the art of the growth technology of pure, lightly doped, and heavily doped (solid solution) nonlinear gallium selenide (GaSe) crystals that are able to generate broadband emission from the near infrared (IR) $(0.8 \mu \mathrm{m})$ through the mid- and far-IR (terahertz (THz)) ranges and further into the millimeter wave $(5.64 \mathrm{~mm})$ range. For the first time, we show that appropriate doping is an efficient method controlling a range of the physical properties of GaSe crystals that are responsible for frequency conversion efficiency and exploitation parameters. After appropriate doping, uniform crystals grown by a modified technology with heat field rotation possess up to 3 times lower absorption coefficient in the main transparency window and $\mathrm{THz}$ range. Moreover, doping provides the following benefits: raises by up to 5 times the optical damage threshold; almost eliminates two-photon absorption; allows for dispersion control in the THz range independent of the mid-IR dispersion; and enables crystal processing in arbitrary directions due to the strengthened lattice. Finally, doped GaSe demonstrated better usefulness for processing compared with GaSe grown by the conventional technology and up to 15 times higher frequency conversion efficiency.

Light: Science \& Applications (2015) 4, e362; doi:10.1038/lsa.2015.135; published online 4 December 2015

Keywords: frequency conversion; GaSe; solid solution crystal; $\mathrm{THz}$

\section{INTRODUCTION}

The $\varepsilon$-polytype of gallium selenide (hereinafter GaSe) has been known since $1934^{1}$ and promises efficient optical frequency conversion and detection over a large range of wavelengths. The performance potential of GaSe, which belongs to the point group symmetry $\overline{6} \mathrm{~m} 2$, can be attributed to its extreme physical properties. GaSe has a broadband transparency window over the range of $0.62-20 \mu \mathrm{m}$ for non-polarized light continues at wavelengths $\geqslant 50 \mu \mathrm{m}^{2,3}$. Other attractive physical properties of $\mathrm{GaSe}$ are its prodigious birefringence $B=0.375$ at $\lambda=10.6 \mu \mathrm{m}$ and 0.79 at terahertz $(\mathrm{THz})$ range ${ }^{4}$, and very high second-order nonlinear susceptibility $d_{22}=54 \mathrm{pm} \mathrm{V}^{-1}$ at $10 \mu^{5}$ and $24.3 \mathrm{pm} \mathrm{V}^{-1}$ in the $\mathrm{THz}$ band $^{6}$. Among the mid-infrared (IR) anisotropic nonlinear crystals, GaSe has the second highest optical damage threshold ${ }^{7,8}$ and thermal conductivity in the plane of the $(0001)$ layers $\left(0.162 \mathrm{~W}(\mathrm{~cm} \cdot \mathrm{deg})^{-1}\right)$, accompanied by large thermal capacity $C_{p}=47.9 \mathrm{~J}(\mathrm{~mol} \cdot \mathrm{deg})^{-1}$ and density $5.05 \mathrm{~g} \mathrm{~cm}^{-3}$, close coefficients of linear thermal expansion $\alpha_{1}$ $=10.8 \cdot 10^{-6} \mathrm{deg}^{-1}$ and $\alpha_{\perp}=9.1 \cdot 10^{-6} \mathrm{deg}^{-1}$, and low two-photon absorption coefficients $0.2-0.5 \mathrm{~cm}^{-1} \mathrm{GW}^{-1}$ for $0.7-0.8 \mu \mathrm{m}$ pumping. The physical properties are well reviewed elsewhere ${ }^{5,9}$.

A GaSe crystal was first used for laser frequency conversion in the mid-IR in $1972^{9,10}$. In subsequent years, GaSe was widely used for inlab mid-IR applications ${ }^{5}$. Over the past two decades, GaSe has been among the most promising nonlinear optical crystals for efficient generation of ultrabroadband radiation $0.8-5640 \mu \mathrm{m}$ (with the exception of the phonon limited gap between $38 \mu \mathrm{m}$ and $58 \mu \mathrm{m}$ ) using birefringent phase matching $(\mathrm{PM})^{9,11-14}$, as well as for electrooptic detection with extremely large $(120 \mathrm{THz})$ bandwidth $^{15}$.

However, in spite of these promising properties, GaSe has not achieved the ubiquity of other nonlinear materials, such as nonlinear $\mathrm{ZnGeP}_{2}$ or electro-optic zinc telluride, in commercial and industrial applications. This lack of application of GaSe is the result of the difficulty in growing and processing large, high optical quality (absorption coefficient $\alpha \leqslant 0.1-0.2 \mathrm{~cm}^{-1}$ ), single crystal samples $^{16-18}$, due to its layered structure with weak interlayer, van der Waals type, bonding ${ }^{9}$. With careful preparation, it is possible to produce optical quality surfaces along the (0001) direction, which is orthogonal to the $c$-axis ${ }^{6}$. Access to other crystallographic directions and fine polishing of exfoliated samples are hampered because GaSe has perfect cleavage and low hardness ${ }^{6,19}$. The hardness of GaSe has been measured to be close to 0 on the Mohs' scale ${ }^{9}$. The limited optical quality of grown GaSe crystals is caused by the weak technological control of defects: point defects (mainly Ga vacancies) and micro-defects ( $\mathrm{Ga}$ precipitates, voids or bubbles, stacking disorders, broken layers, and dislocations) $)^{20,21,22}$. In particular, the dislocation density can reach $10^{9} \mathrm{~cm}^{-2} 22$, and the fraction of layer stacking faults may be up to $0.67^{23}$. Moreover, low layer bonding gives rise to the existence of four $(\varepsilon, \delta, \gamma$, and $\beta)$ polytypes ${ }^{9}$ that can found in a single sample, further limiting its applications. As a result, the physical

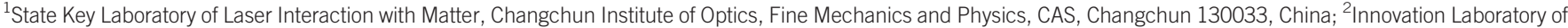

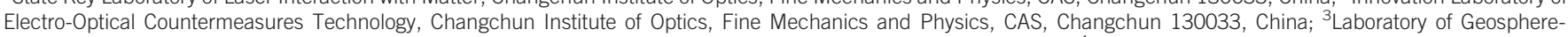

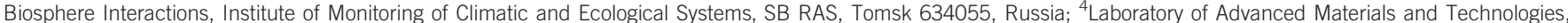

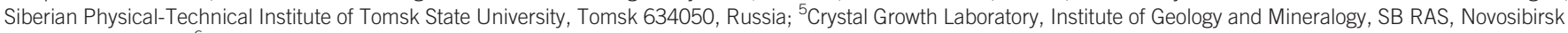
630090, Russia and ${ }^{6}$ Novosibirsk State University, Novosibirsk 630090, Russia

Correspondence: VA Svetlichnyi, Email: v_svetlichnyi@bk.ru

Received 24 December 2014; revised 20 August 2015; accepted 20 August 2015; accepted article preview online 22 August 2015 
properties of GaSe are strongly dependent on the state-of-the-art of the growth technology, as well as on the specifications of the measurement facility used, and the experimental conditions. Finally, the physical properties reported for GaSe in over 2000 published papers are highly variable; the optical properties for the e-wave remain unstudied or are inconsistent. To fully exploit the potential of GaSe and to expand its applications, it is necessary to overcome these limitations, i.e., to improve further its physical properties.

Fortunately, GaSe is a good matrix material for doping with various impurities. The original $\varepsilon$-polytype structure of GaSe is strengthened by doping; meanwhile, the physical properties responsible for the efficiency of frequency conversion and the possibility of electro-optic applications may be noticeably modified. However, due to the negative effect on optical nonlinearity of doping by sulfur, the first agent explored $^{24}$, only a few other dopants (In, Te, Er, and Ag), in limited concentration ranges, were used until the last decade to modify further physical properties for nonlinear optical applications ${ }^{19,21,25,26}$. In addition, these studies are mostly related to the physical properties of the ordinary light waves. Regardless, impressive technological progress in GaSe doping has been achieved and intensive studies of the physical properties have been performed during the last decade by a few research teams, showing a number of detailed results that have not typically been systematically studied. However, there are some serious contradictions in these results. While mid-IR applications and $\mathrm{THz}$ generation by optical rectification and down-conversion in GaSe have been studied in detail ${ }^{5,12,14,15,27,28}$, very few works are devoted to the experimental study of $\mathrm{THz}$ emission generation in doped GaSe. In this regard, a topical issue is the need to summarize and analyze the obtained data on the physical properties of doped GaSe crystals. In this review, we present the progress in the modification of the physical properties of GaSe crystals by light and heavy doping or solid solution crystal growth as well as the application of GaSe crystals for frequency conversion. We hope these data can be used for further modification of the GaSe physical properties and will aid in the crystal selection for and optimization of parametric frequency converters.

\section{CRYSTAL GROWTH AND SAMPLE FABRICATION}

Pure and doped GaSe crystals are obtained by different methods, but the most common method is the vertical Bridgman method ${ }^{29,30}$. We proposed the use of a single-zone furnace while gradually moving the ampoule inside ${ }^{16}$. This technique seems more reliable because the vapor pressure inside the ampoule may be estimated visually by its color. To improve the optical quality of the synthesized material, the synthesis may be conducted in quartz ampoules that are heavily charged, up to $65 \%$ by volume, to decrease the quantity of rest gases (Figure 1a).

The constituent materials were preliminary purified by multiple remelting. Synthesized material is then stored in sealed ampoules (Figure 1b) before being transferred into a single- or double-wall ampoule for crystal growth.

The growth ampoules coated with pyrolytic carbon are used to prevent interaction with the quartz walls. Both unseeded ${ }^{31}$ and

a

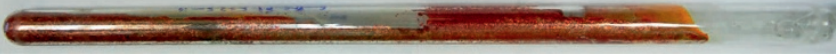

b

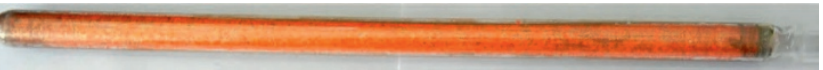

Figure 1 (a) Ampoules with as-synthesized polycrystalline GaSe:S (3 mass.\%) and (b) GaSe:S (5 mass.\%) in a store. seed-aided ${ }^{32}$ growth produce single crystals with (0001) layers parallel to the growth axis because layered crystals tend to grow along the primary thermal gradient. Thus, most of the GaSe crystals grown were naturally oriented with the (0001) plane along the growth axis (Figure 2), which is inconvenient in practice.

We demonstrated that application of a rotating heat field ${ }^{33}$ helps considerably in resolving this problem. As a result, a set of GaSe crystals with sub-orthogonal orientation of the cleavage plane to the growth axis was obtained ${ }^{34-36}$.

The doping of GaSe is achieved by intercalation techniques (ion implantation or laser intercalation $)^{37,38}$, annealing in the presence of a doping agent vapor ${ }^{39}$, direct thermal diffusion from dopants in contact with the crystal, or its direct addition into the melt. We found that the doping effect on the physical properties strongly depends on the dopant group, the dopant's ability to form isostructural binary compounds, the number of dopants incorporated and their concentrations, as well on the doping method used. To study all the possibilities, extended sets of doped GaSe crystals were grown from the melts by the vertical Bridgman method incorporating heat field rotation at the Institute of Geology and Mineralogy of SB RAS, Novosibirsk, which were then processed and used for laser frequency conversion. Some of the crystals grown were doped with isovalent elements S, In, and Te, which form isostructural binary compounds, GaS, InSe, and GaTe, respectively. Namely, GaSe:S $(0.05,0.15,0.3,0.5,0.9,1,2,2.3$, $2.5,3,4,5,7,10,10.2,11$, and 100 mass.\%) or $\mathrm{GaSe}_{1-x} \mathrm{~S}_{x}(x=0.002$, $0.007,0.014,0.023,0.04,0.046,0.09,0.103,0.112,0.133,0.175,0.216$, $0.294,0.406,0.412,0.44$, and 1), GaSe:In (0.01, 0.1, 0.5, 1, 2, 3, and 5 mass.\%) or $\mathrm{Ga}_{1-x} \mathrm{In}_{x} \mathrm{Se}(x=0.0001,0.001,0.007,0.013,0.026,0.04$, and 0.07$)$, and GaSe:Teb $(0.05,0.1,0.5,1,2,5$, and 10 mass.\%) or $\mathrm{GaSe}_{1-x} \mathrm{Te}_{x},(x=0.0006,0.001,0.06,0.012,0.024,0.06$, and 0.12$)$ crystals were formed by charge composition. This type of doping was also realized in another way, i.e., via growth from the melt of binary compounds, such as GaSe:InSe (1, 5, 20 mass.\%), GaSe:InS (1, 5, 20 mass.\%) or GaSe:GaS (1, 5, 20 mass.\%). Doping was also performed with isovalent $\mathrm{Al}$, which does not form a binary compound $\mathrm{AlS}^{40}$, and Er, whose binary compound ErSe does not form an isostructural (but a cubic) lattice ${ }^{41}$. As a result, $\mathrm{GaSe}: \mathrm{Al}(0.01,0.05,0.2,0.5,1,2$ at.\%) and GaSe:Er $(0.025,0.1,0.5,1,2$ at. \%) crystals were also grown. Doping with non-isovalent $\mathrm{Ag}$ is achieved by growth from the melt GaSe:AgGaSe 2 (10 mass.\%). Two-element doped GaSe was grown from the melt with two isovalent elements, one of which $(\mathrm{Al})$ does not form a binary compound: GaSe:In (0.75 mass.\%):Al (0.02 at.\%), as well from the melt with one isovalent $(\mathrm{S})$ and one non-isovalent (Ag) element: GaSe:AgGaS 2 (10.6 mass.\%). We found that all the doped GaSe crystals still belong to the $\varepsilon$-polytype point group and possess a layered structure, with higher hardness and a lower propensity to cleavage. The layer orientation for the doped crystals is quasiorthogonal to the growth direction, similar to that of the GaSe crystals. Visual inspection of as-grown crystals did not show any color differences between the initial and final sections of the boules; the high optical quality of the crystals can be estimated by the naked eye, evident by its transparency and homogeneity (Figure 3 ).

No eutectic aggregate was found on the top surfaces of the boules (Figure 3a), indicating that all additional components are distributed inside the crystal. This observation confirms that the application of the rotating heat field method is effective in improving convection in the vertical Bridgman technique.

Two types of sample were fabricated and studied. One type was cleaved from the as-grown boules, i.e., had faces orthogonal to the $c$-axis, so that the incident light beam was parallel to the (0001) axis. 

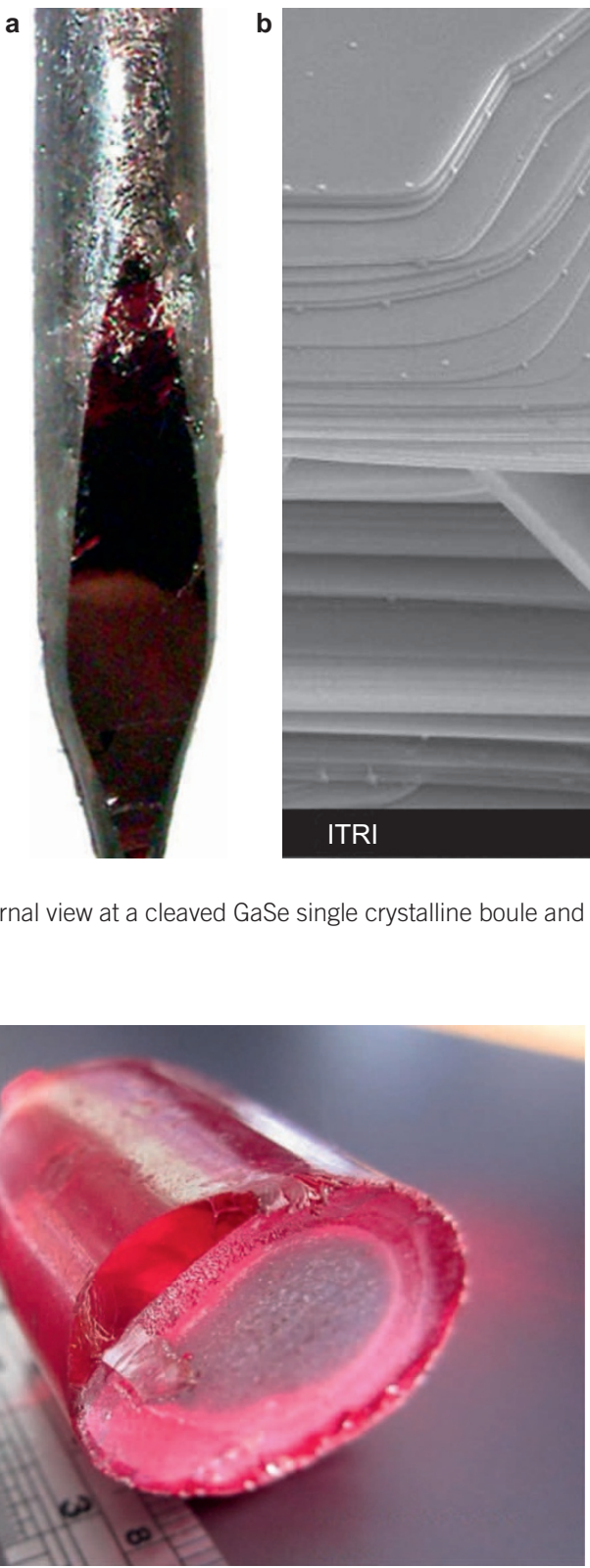

a

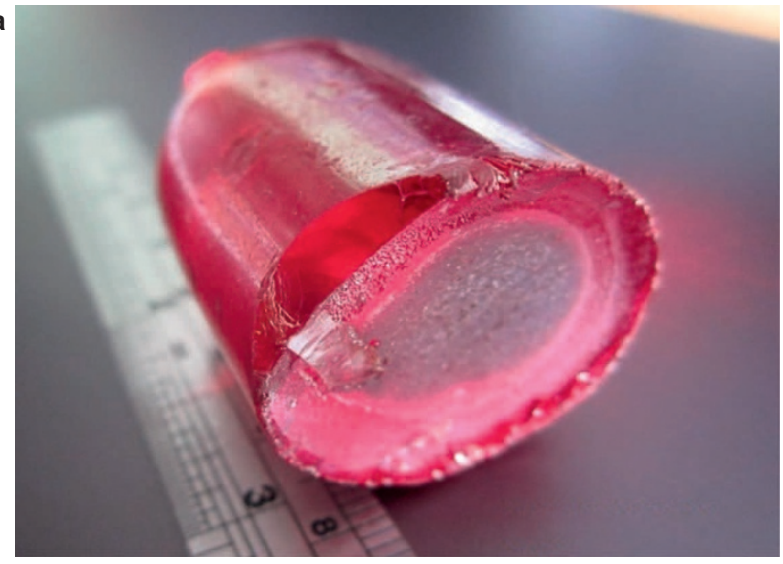

C

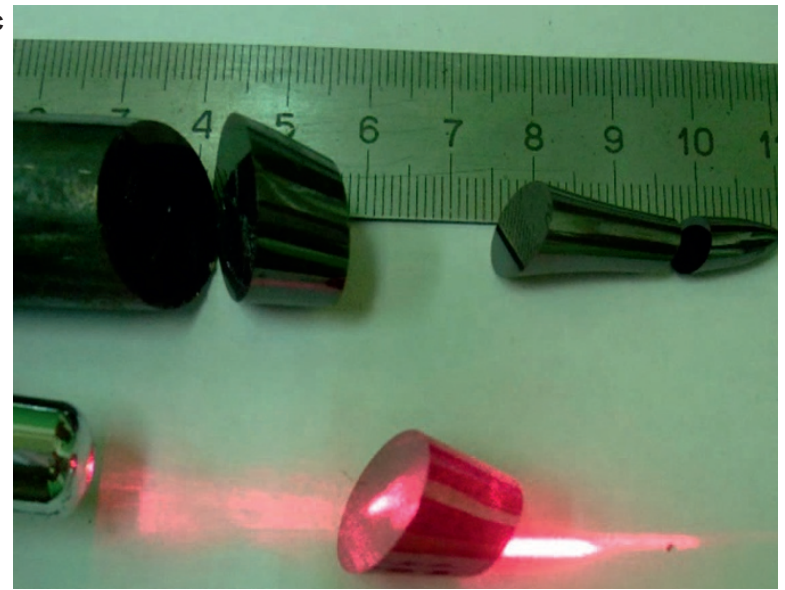

b

SEI $\quad 15.0 \mathrm{kV} \quad \times 5,000 \quad 1 \mu \overline{\mathrm{m}}$ WD $12.2 \mathrm{~mm}$

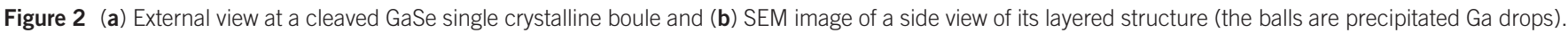

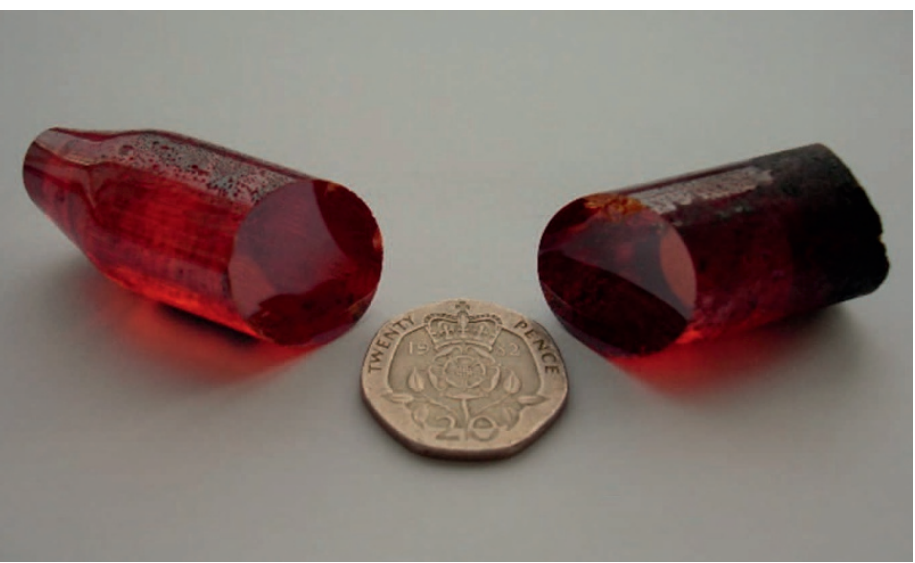

d

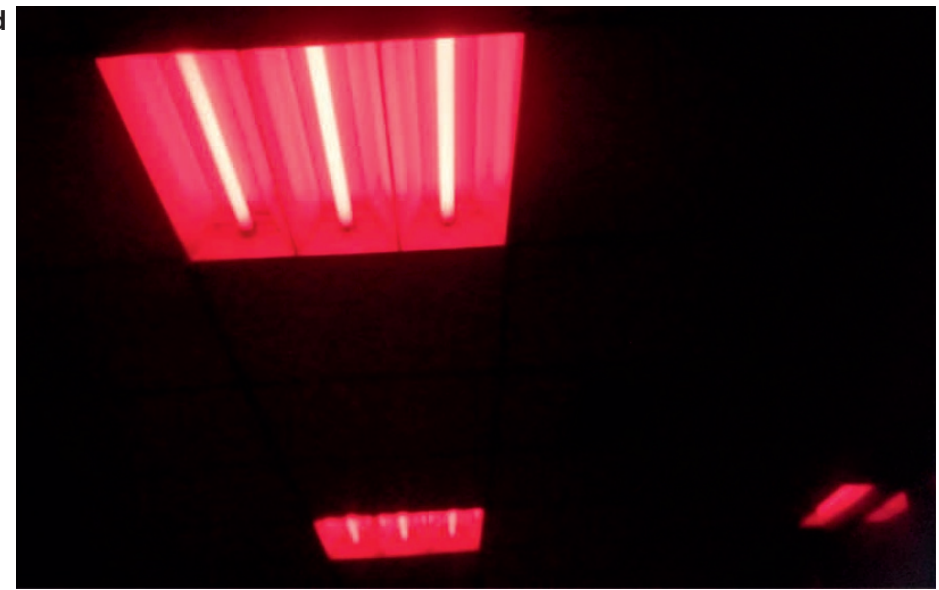

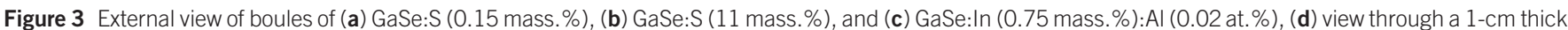
GaSe crystal of daylight lamps. 

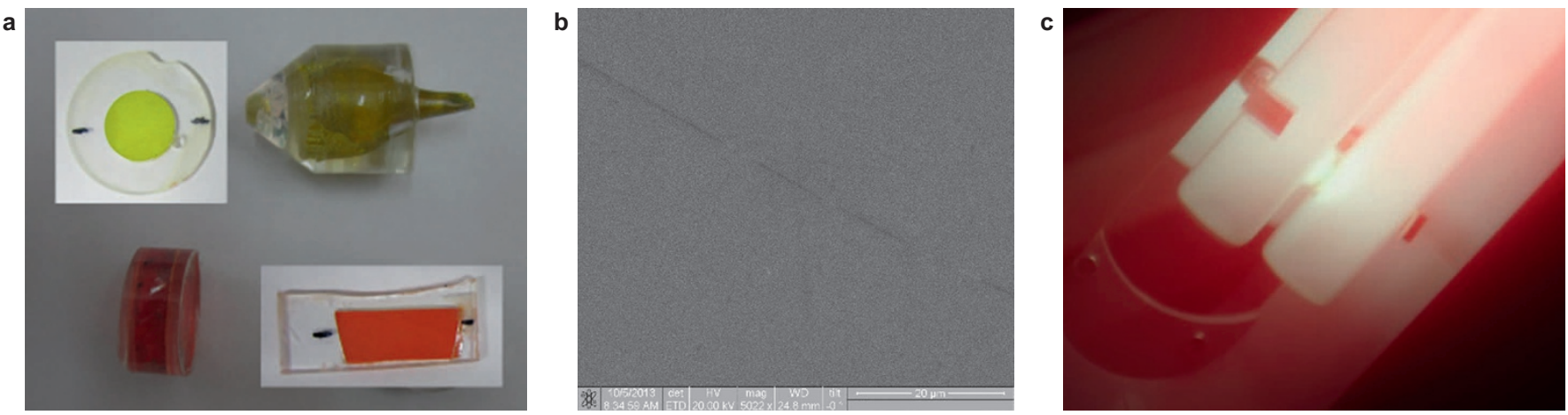

Figure 4 (a) GaS (on top) and GaSe:S (11 mass.\%) (on bottom) in polymethyl acrylate holders and their processed sections; the layer directions are denoted by punctures, (b) the surface morphology with a spatial resolution $10 \mu \mathrm{m}$ for GaSe:S (11 mass.\%) processed orthogonal to the layer structure, (c) view through processed GaSe:S (2 mass.\%) crystal of a daylight lamp.

The samples were easily cleaved with high-quality surfaces until the end of the crystals. The second type of sample was mechanically processed. First, a section of a $\mathrm{GaSe}_{1-x} \mathrm{~S}_{x}$ boule was immersed in a monomer (polymethyl acrylate) mixed with a thermoinitiator and then placed in an oven for polymerization for 2 hours (Figure 4a).

The surface quality of the cut and polished samples was found to be suitable for e-wave studies (Figure $4 \mathrm{~b}$ and $4 \mathrm{c}$ ). Thinner samples possess high concentrations of defects (cracks and deformations) and were useless for these studies; some samples were polished with large diameter $(9 \mu \mathrm{m})$ polishing powder for comparison.

\section{CRYSTAL CHARACTERIZATION}

The accuracy of modern facilities for composition determination, such as Inductively Coupled Plasma - Optical Emission Spectrometers (ICP-OES) iCAP 6500, Thermo Scientific, were found to be inadequate to determine the presence of low solubility dopants, such as $\mathrm{Ag}, \mathrm{Al}$, or $\mathrm{Er}^{36,42-44}$, in quantities that, though small, may still greatly influence the physical properties of the crystals. Thus, these current techniques do not allow for establishment of the dependence of optical quality of doped GaSe on the Ag, Al, or Er contents.

In some papers, the concentration of well-incorporated dopants in GaSe was found to depend on the charge ${ }^{39,45,46}$; however, this finding is only valid for noticeable dopant concentrations. For small quantities of volatile dopants, a significant proportion can interact with the ampoule wall. Moreover, a segregation phenomenon was observed for In-doped GaSe; solid solutions can also be present in dissimilar crystallized phases, depending upon their tendency toward differing compositions $^{29}$. For solid solutions, the segregation process is often a common feature due to the different solidification temperatures for the parent crystals. This feature leads to variability in the composition over the crystal bulk, which should be determined and accounted for in studies and applications ${ }^{47,48}$, as well as when identifying the polytypic composition. As a result, we label crystals in accord with their charge composition.

Due to the limited penetration of X-rays, polytype composition of GaSe cannot be established by X-ray methods throughout the bulk crystals $^{17}$. Thus, to minimize the discrepancies between the data on doped GaSe properties, it is necessary to estimate the crystal composition and structure for every sample, even if it is only of micrometerscale thickness, for $\mathrm{THz}$ applications. The polytype structure of the observed specimens in our study was identified by a proposed nonlinear method ${ }^{17}$, through a comparison of the $\varphi$-angle dependence of frequency conversion efficiencies for different types of three wave interactions. In Ref. 17, a nonlinear method for determining optical uniformity is also presented.

The absorption coefficient for the maximal transparency window of the grown crystals was estimated to be up to $2-3$ times lower $(\leqslant 0.03-$ $0.06 \mathrm{~cm}^{-1}$ ) than that for crystals grown by the conventional Bridgman method. Therefore, for sub-mm-thick and mm-thick samples, the best quality crystals cannot be selected, due to the limited absorptivity. We proposed a selection criteria, determined by an absorption measurement outside of the maximal transparency range, by examining the parameters of the exciton and phonon absorption peaks: the larger the peak magnitude and the narrower the spectral bandwidth, the better the quality ${ }^{49,50}$. To determine adequate absorption coefficients and refractive indices by THz-TDS, a criterion was proposed based on the interference pattern shape-form in the recorded spectra ${ }^{51,52}$. The validity of this method was confirmed by the efficiency of different frequency conversion processes.

\section{SPECIFIC FEATURES OF THE GROWN CRYSTALS}

We found that the prospects for modifying GaSe physical properties are strongly dependent on the dopant ability to form a binary isostructural compound. $\mathrm{S}$ and $\mathrm{Te}$ (anions) and In (cation), generating binary isostructural compounds $\mathrm{GaS}, \mathrm{GaTe}$, and InSe, respectively, may form solid solution crystals $\mathrm{GaSe}_{1-x} \mathrm{~S}_{x}^{24,53-62}, \mathrm{GaSe}_{1-x} \mathrm{Te}_{x}^{46,49,56,61-66}$, and $\mathrm{Ga}_{1-x} \mathrm{In}_{x} \mathrm{Se}^{19,25,26,67-69}$, where $x$ is the mixing ratio of the parent binary compounds. The closer the match in the atomic size of the substituting atoms, the larger the mixing ratio of solid solution crystals that may be grown with suitable optical quality, as in the following: $\mathrm{GaSe}_{1-x} \mathrm{~S}_{x}$ with $x \leqslant 0.44$ (11 mass. \% of S $)^{51}, \mathrm{Ga}_{1-x} \mathrm{In}_{x} \mathrm{Se}$ with $x=0.03(2.32$ mass.\%) of $\operatorname{In}^{55}$, and $\mathrm{GaSe}_{1-x} \mathrm{Te}_{x}$ with $x=0.012(1 \text { mass. } \%)^{49}$. In turn, the higher the permitted limit in the mixing ratio, the wider the variation in the optical and mechanical properties that can be achieved. Moreover, substitution, vacancy occupations, interstitials, and interlayer intercalation ${ }^{70}$, all influence the physical properties in intricate ways.

We found that the inability to form binary (AlSe) or isostructural binary (ErSe) compounds leads to an inability to form solid solution crystals. Therefore, the solubility of the following types of dopants is very limited and is difficult to measure accurately: $\leqslant 8 \times 10^{-2}$ for $\mathrm{Al}^{36,42,50}$ and $5 \times 10^{-4}$ for $\mathrm{Er}^{21}$. The available data for 0.5 at. $\% \mathrm{Er}$ doping of GaSe by charge composition is claimed to have resulted in a $24 \%$ increase in the intrinsic nonlinearity ${ }^{71}$; this result appears to be inconsistent, as Er has such low solubility. Regardless, an improvement in the optical quality with $\mathrm{Al}$ and Er doping was also observed. 
Because dopants can occupy vacancies, generate interstitials or interlayer intercalations ${ }^{70}$, or form precipitations, we propose that, in this case, only the vacancy occupation process may lead to improvement in optical quality. The decreased vacancy concentration may also cause a decrease in the stacking fault density and further improve the optical quality.

Recently, doping with isovalent elements was achieved by adding the charge isostructural binary compounds: $\operatorname{InSe} e^{43}, \mathrm{InS}^{34}$, and $\mathrm{GaS}^{72}$. Doping with InSe or $\mathrm{GaS}$ is found to be similar to In or $\mathrm{S}$ doping, respectively, or the growth of ternary solid solution crystals $\mathrm{Ga}_{1-x} \mathrm{In}_{x} \mathrm{Se}_{x}$ or $\mathrm{GaSe}_{1-x} \mathrm{~S}_{x}$; somewhat better dopant distributions were established for the case of doping with InSe or GaS. Doping with InS is equivalent to two-element doping or the growth of quaternary solid solution $\mathrm{Ga}_{1-y} \mathrm{In}_{y} \mathrm{Se}_{1-x} \mathrm{~S}_{x}$ crystals, which resulted in approximately $12 \%$ higher In solubility for GaSe:InSe (5 mass.\%) $)^{34}$. Doped crystals were also grown from the melt of GaSe and other structure ternary compounds: GaSe:AgGaSe ${ }_{2}^{26,44,73}$ and GaSe:AgGaS ${ }_{2}{ }^{42}$. GaSe:AgGaSe ${ }_{2}$ (10 mass.\%) are identified as GaSe doped with 0.04 mass.\% Ag but GaSe:AgGaS 2 (10.6 mass.\%) as GaSe doped with 1.94 mass.\% S and 0.06 mass. \% of Ag. Thus, the solubility of non-isovalent Ag is close to that for $\mathrm{Al}$, which does not form binary compounds and Er that does not form isostructural compounds, resulting in an almost identical effect on the optical properties. This result is possibly due to vacancy occupation and a decrease in stacking fault density. This result stimulated us to study other combinations of two dopants: In and $\mathrm{Al}$ (Figure 3), as well S and Al-doped GaSe crystals, which were then grown.

\section{OPTICAL PROPERTIES OF GaSe DOPED WITH ISOVALENT ELEMENTS FORMING ISOSTRUCTURAL BINARY COMPOUNDS}

\section{S-doped GaSe}

Incorporation of the small atoms of $S$, which form an isostructural binary compound GaS, into GaSe can be easily identified from different optical spectra and even estimated quantitatively. In Figure 5, a regular transformation of shape forms and a linear spectral shift of Raman scattering peaks is observed with increasing of S-content.

The regular transformation is in effect up until the sulfur content of 11 mass.\%; this result indicates that these S-doped crystals are of the $\varepsilon$ polytype structure similar to that of GaSe and useful for nonlinear applications. Figure 6 demonstrates a linear spectral shift of maximal transparency edges for GaSe versus S-content, which is extremely important in practice.

The short-wave edge shifts from $620 \mathrm{~nm}$ down to approximately $540 \mathrm{~nm}$ (Figure 6b). This shift almost removes the nonlinear two

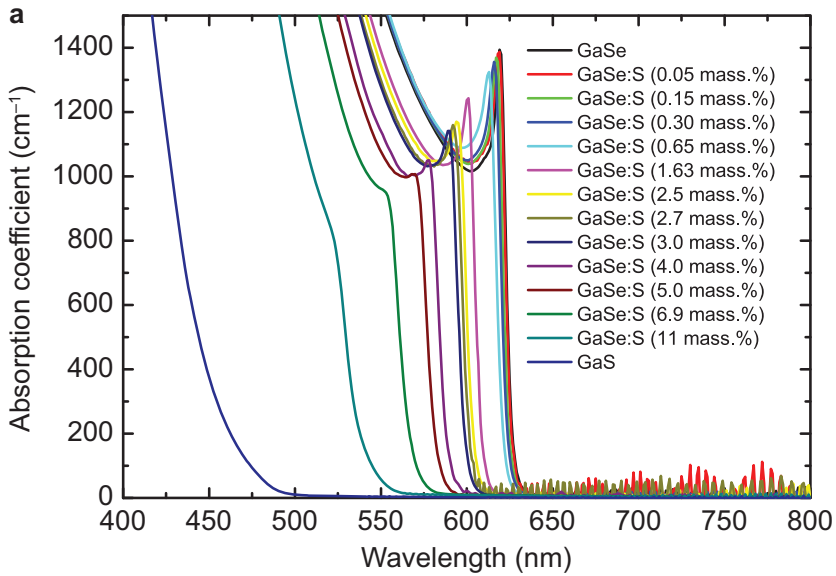

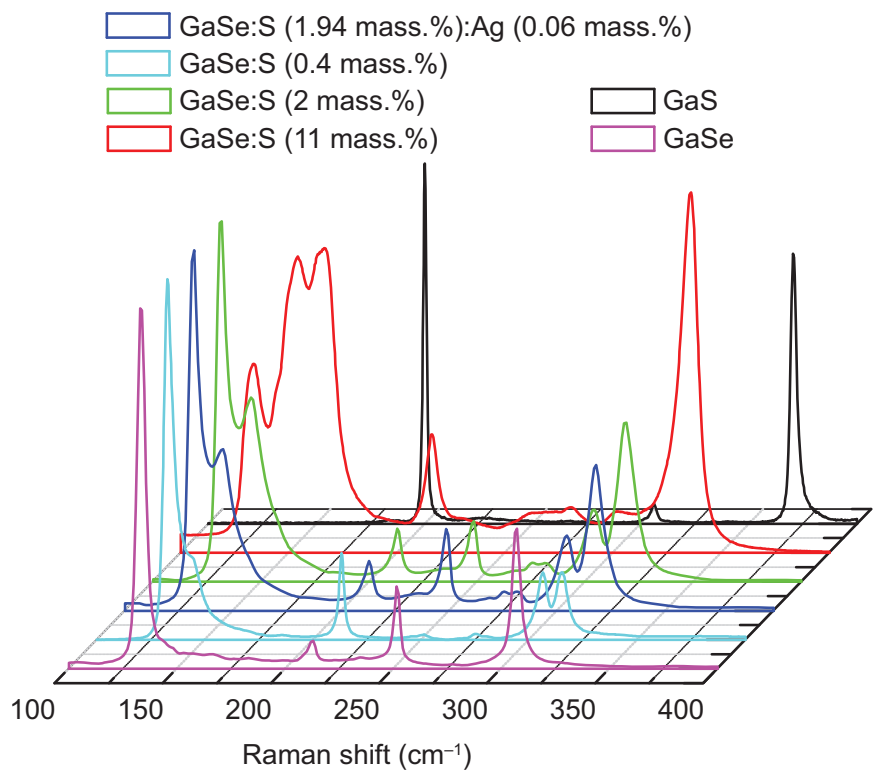

Figure 5 Raman scattering spectra for GaS, GaSe, and solid solutions $\mathrm{GaSe}_{1-x} \mathrm{~S}_{x}$

photon absorption for a near-IR laser pump $p^{7,74,75}$ and shifts the PM curves for parametric frequency conversion processes in the same direction, allowing for optimization by S-content control. However, the short-wave shift of the PM curves results in the necessity to design dispersion equations as a function of the mixing ratio ${ }^{55}$. In addition, the shift of the long-wave edge from $20 \mu \mathrm{m}$ down to $14 \mu \mathrm{m}$ limits the long-wave cutoff of difference frequency generation (DFG).

\section{In- and Te-doped GaSe}

Limited incorporation of heavier In-atoms in GaSe leads to an insignificant shift of absorption edges toward the long wave ${ }^{69}$ and a small change of the PM conditions. Very small incorporation of heavy Te atoms, with consideration for a wavelength accuracy of $\pm 1 \mathrm{~nm}$ in common commercial spectrometers, results in a barely resolved shift of absorption edges (Figure 7) and Raman peaks (Figure 8) toward the long wave.

Taking into account the small concentration of incorporated Te, we propose that the noticeable shift in Figure $7 \mathrm{a}$ of the short-wave edge for

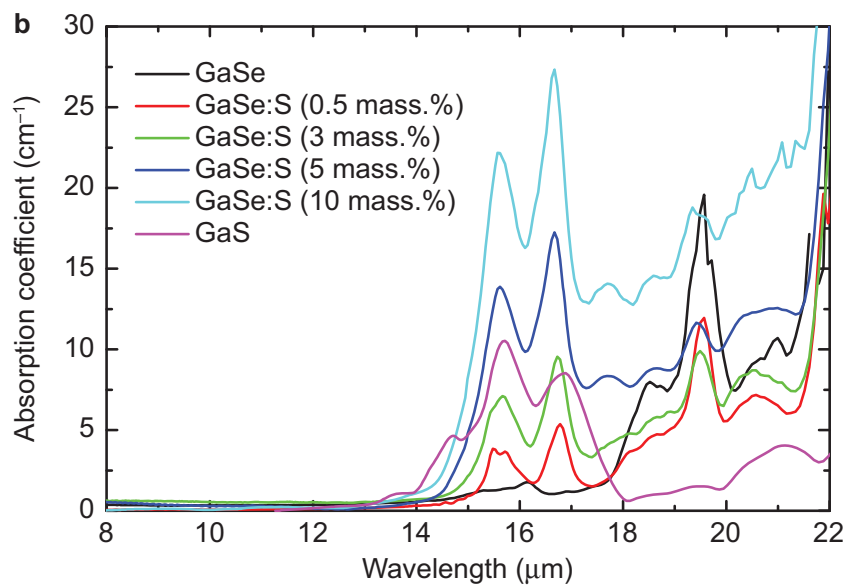

Figure 6 (a) Short- and (b) long-wave edge absorption spectra for GaSe, GaS, and solid solutions GaSe ${ }_{1-x} \mathrm{~S}_{x}$. 

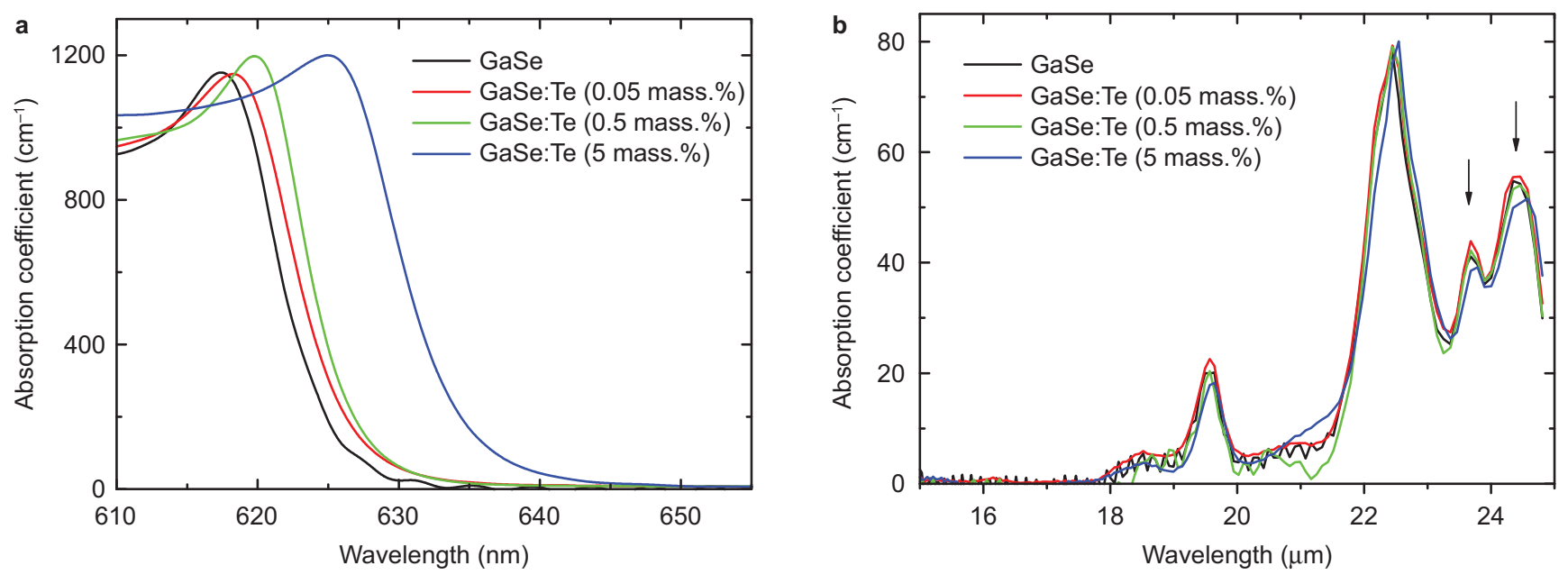

Figure 7 (a) Short- and (b) long-wave edge absorption spectra for GaSe, GaS, and solid solutions GaSe $e_{1-x} \mathrm{Te}_{x}$.

heavily doped GaSe:Te ( 5 mass.\%) is caused by the presence of other crystal phases. For GaSe doped with isovalent elements, forming isostructural binary compounds, the absorption spectra are found to be independent of the doping method. For In- and Te-doped crystals, new dispersion equations should be designed with consideration of frequency conversion processes of the wavelengths interacting near the PM cutoff.

Small spectral shifts in the Raman scattering peaks with doping (Figure 8), as well as barely observable changes in the shapes of multiphoton absorption peaks, labeled in Figure 7b by arrows, confirm once more the weak Te incorporation in GaSe. Figure 5 shows, for example, that the Raman spectra for GaSe:S (2 mass.\%) and GaSe:S (1.94 mass.\%):Ag (0.06 mass.\%) are quite similar, in spite of the small difference in Ag content.

MID-IR PROPERTIES OF AI-, Er-, AND Ag-DOPED CRYSTALS

No shift was detected in the short- and long-wave edges in the absorption spectra for isovalent Al-doped crystals, which does not form binary compounds. Nevertheless, the transformation of the profiles

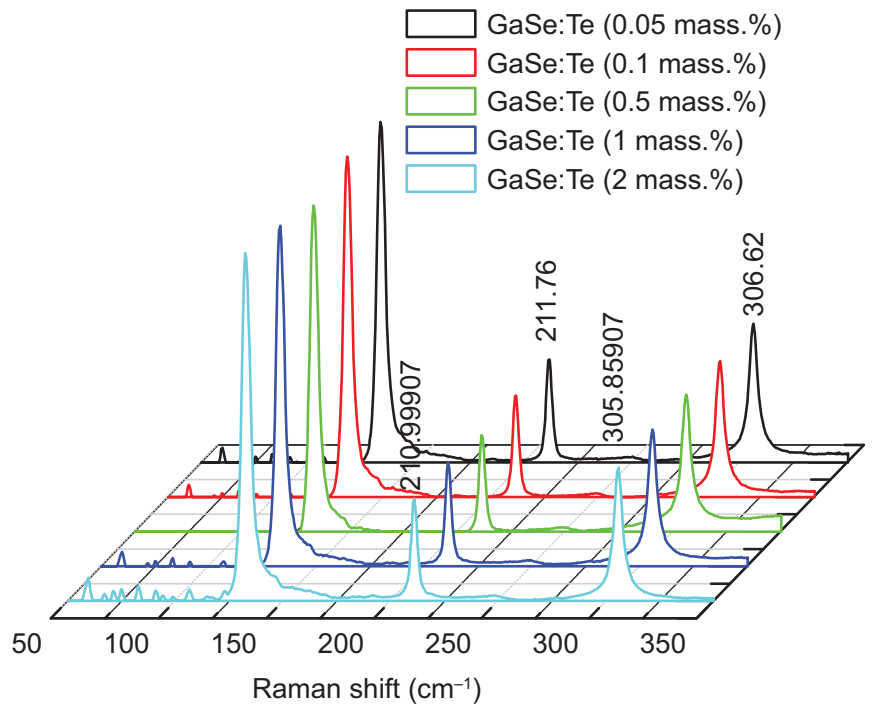

Figure 8 Raman scattering spectra for GaSe and GaS and solid solution $\mathrm{GaSe}_{1-x} \mathrm{Te}_{x}$ of the short wave (exciton) (Figure 9) and the Raman (at $213 \mathrm{~cm}^{-1}$, Figure 10) peaks confirm the increasing incorporation of $\mathrm{Al}$ with its increased concentration in the charge. The transformation of the Raman peak, at $213 \mathrm{~cm}^{-1}$ with increasing $\mathrm{Al}$ content (Figure 10 inset) is classified as being related to the impurity levels ${ }^{76}$.

Exciton spectra in point-to-point measurements were not reproduced well. We propose that this lack of reproducibility is a result of poor technological control of Al-doping levels and uniformity of distribution, as illustrated in the Figure 9a inset. In the inset of the second harmonic generation (SHG) PM curve, no differences in $\mathrm{CO}_{2}$ laser SHG PM angles for GaSe and GaSe:Al is observed, which confirms once again that there is no shift in the transparency range.

GaSe:Al possesses Raman spectra very similar to that of GaSe doped with isovalent Er (Figure 10b) whose binary compound is not isostructural to GaSe.

In the second case, possibly due to the much larger atomic size of Er atoms compared to $\mathrm{Al}$ atoms, some transformation in $248 \mathrm{~cm}^{-1}$ peak with increasing Er content can be seen in Figure 10. This peak is attributed to defect levels resulting from impurities also ${ }^{76}$, again confirming Er incorporation. Very similar optical properties to that for Al- and Er-doped crystals were observed for GaSe doped with not isovalent $\mathrm{Ag}$, which does not form binary isostructural compounds.

\section{OPTICAL PROPERTIES IN THE THz REGIME}

Very recently, for the first time, dispersions and anisotropy of absorption coefficient for pure and S-doped GaSe were studied in detail in the $\mathrm{THz}$ regime, using both cleaved and processed samples ${ }^{51}$. With further study, the extraordinary refractive index for GaSe was found to be significantly lower, and the birefringence was found to be larger, than those values calculated using data from (Figure 11). ${ }^{3,77,78}$ The dispersion equations for the ordinary refractive index referred to in papers $^{3,77,78}$ have a common origin in Palik's paper ${ }^{79}$, which resulted in the similarity of the calculated curves (Figure 11a).

Extraordinary dispersion is determined primarily by a semiempirical method using PM data measured at different experimental conditions, which resulted in inconsistent dispersion equations. In particular, a pair of Vodopyanov's dispersion equations ${ }^{77}$ recommended by the widely used Handbook ${ }^{5}$ demonstrates a maximal difference in $\mathrm{THz}$ birefringence, $\mathrm{B}=0.49$, to that calculated using other dispersion equations (Figure 11a) or known experimental data, $\mathrm{B}=0.79^{4,80}$. It was established by comparison that the best 

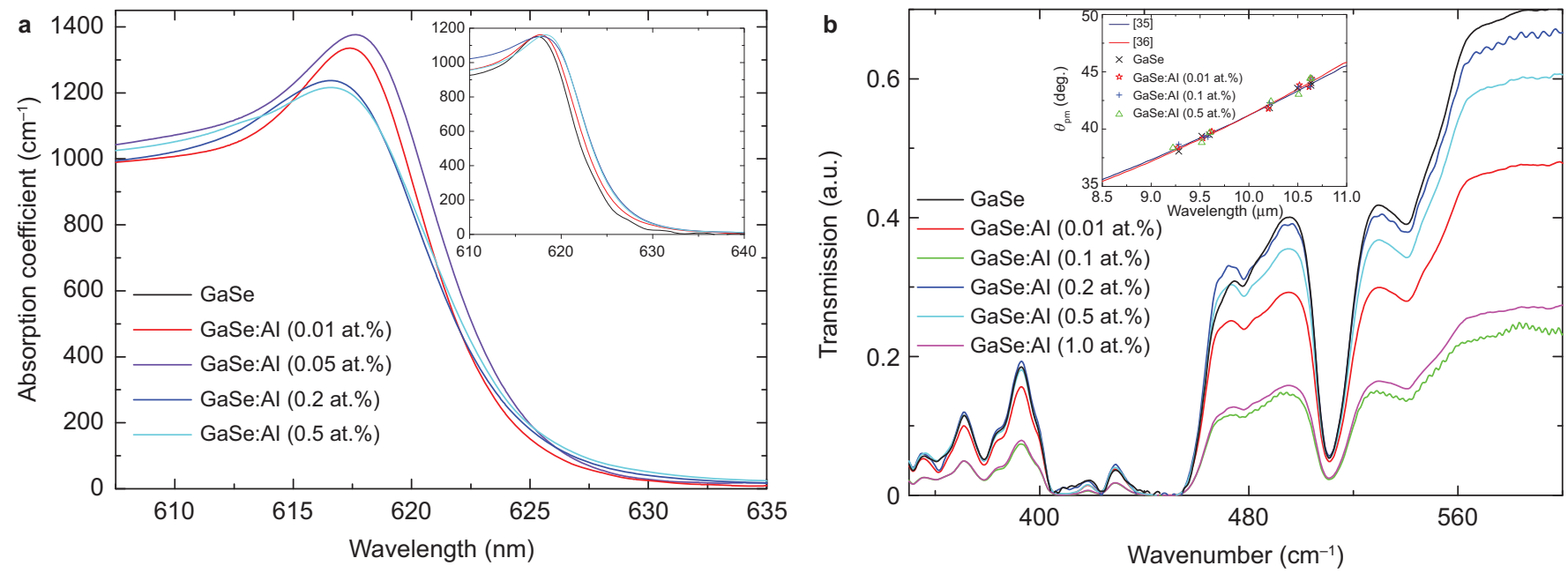

Figure 9 (a) Short- and (b) long-wave edges of the absorption spectra pure and Al-doped GaSe. Not reproduced changes in exciton absorption peak are shown in the figure (a) inset. SHG phase matching curve is shown in the figure (b) inset.

dispersion equations for $\mathrm{THz}$ range have been proposed by Chen et $a l .^{3}$ The ordinary and extraordinary refractive indices for solid solutions $\mathrm{GaSe}_{1-x} \mathrm{~S}_{x}$ decrease in proportion to the mixing ratio magnitudes, from GaSe to GaS. Thus, the S-content in GaSe can be estimated from the refractive indices.

One of the most attractive results of the study is the possibility of engineering the dispersion properties in the $\mathrm{THz}$ range, independent of the dispersion properties within the maximal transparency window. Any doping in GaSe, a p-type semiconductor crystal, results in a change in the free charge carrier concentration, which affects the $\mathrm{THz}$ o-wave absorption coefficient, and furthermore, the ordinary refractive index (Figure 11b). Surprisingly, doping with Al leads to an extremely large, from five to seven orders of magnitude, decrease in the free charge carrier concentration. In turn, doping with Al leads to a large shift of the plasma frequency toward the long wave, as well a decrease of the plasma absorption coefficient ${ }^{36,42}$. As a result of the negative input of the plasma, the dielectric response of GaSe in the $\mathrm{THz}$ range significantly decreases, and the ordinary refractive index grows markedly (Figure 11b), as well as birefringence (Figure 12a). Nevertheless, the extraordinary index remains almost unchanged, similar to the lack of change in the e-wave absorption coefficient due to the strong absorption anisotropy of plasma.

Moreover, the dispersion properties in the visible to mid-IR ranges remain almost independent of the plasma input. This result suggests a

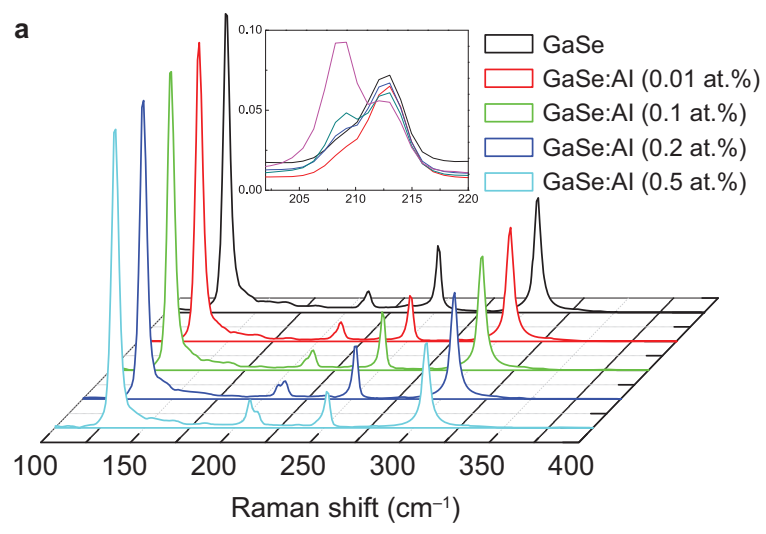

very attractive possibility for PM control and optimization, as well for applications in polarization optics. Additional control of THz dispersions was achieved by temperature tuning (Figure 12b). Notably, the phonon absorption structure and peaks in doped GaSe are transformed with increasing dopant concentration ${ }^{49,51}$, which should be reflected in changes of the dispersion properties. As a result, the widely used formulae for estimating dispersion properties of solid solution crystals, from the visible to mid-IR range, calculated from the dispersions data of parent crystals ${ }^{81}$ cannot be applied to estimations in the $\mathrm{THz}$ range.

\section{PHASE MATCHING}

Pure and doped GaSe have the advantage that they can be used to construct a simple mid-IR or THz-wave generation system, as collinear phase-matched DFG eliminates the complexity of angle tuning both the input and output beams. Moreover, not only pure, but even heavily doped, GaSe crystals have rich possibilities for PM (Figure 13); specially designed dispersion equations were used in these calculations ${ }^{35}$.

Figure 13a shows that a forward-wave optical parametric generator (OPG), under $\mathrm{CO}_{2}$ laser pumping can cover almost the entire longer wavelength range by continuously tunable emission. Six types of frequency interactions can be realized in such an OPG, providing rich possibilities for maximizing generation efficiency, especially if we bear

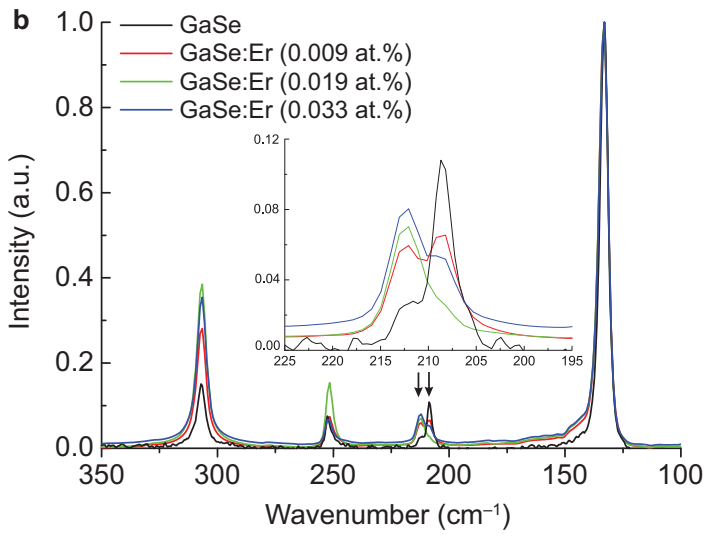

Figure 10 Raman spectra for (a) GaSe:Al and (b) GaSe:Er. 

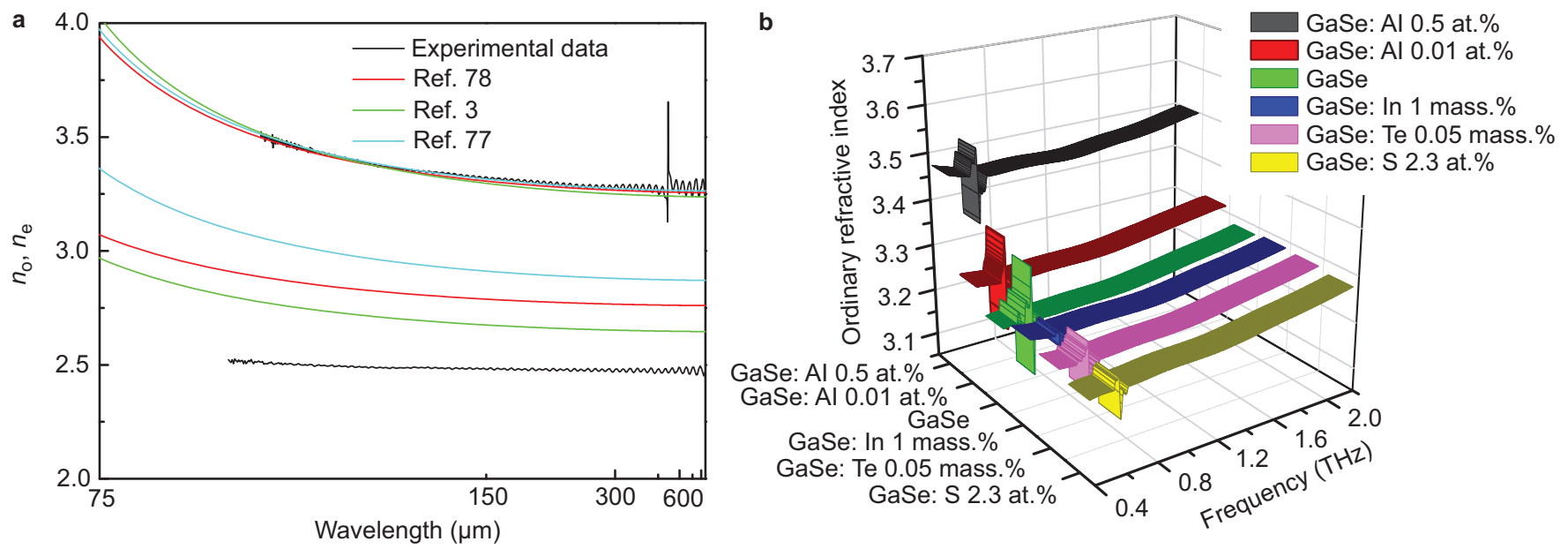

Figure 11 (a) THz dispersions for pure and (b) ordinary refractive index dispersions for S-, In-, Te-, and Al-doped GaSe.

in mind the strong anisotropy of the mid- $\mathrm{IR}^{82}$ and $\mathrm{THz} \mathrm{z}^{51}$ absorption, and the possibility of temperature controlled tuning. Moreover, the uncommon ee-e type of three-wave interaction can be realized ${ }^{80}$. Figure 13b shows the PM for ee-e type DFG, by a two-frequency $\mathrm{CO}_{2}$ laser, is realized at large PM angles, i.e., with low efficiency due to the GaSe lattice symmetry. Short-wave pumping should be much more efficient (Figure 13c); shorter-wave pumping is also preferable from the practical point of view. Figure 13d demonstrates significant changes in SHG and DFG PM angles; the SHG efficiency can be significantly improved for long-wave pumping. For appropriately chosen crystals, temperature controlled PM can be realized for the uncommon oo-o type of three-wave interaction. Moreover, thermooptical coupling in GaSe was studied by modeling for the first time, taking into account its prodigious birefringence and huge thermal anisotropy $^{83}$.

\section{FREQUENCY CONVERSION: OPTIMAL DOPING}

The second-order nonlinear susceptibility coefficient for GaSe heavily (10 mass. \%) doped with light $\mathrm{S}$ or for solid solution $\mathrm{GaSe}_{0.6} \mathrm{~S}_{0.4}$ crystal grown by conventional technology is only 0.31 of that for $\mathrm{GaSe}^{24}$. As large an increase in the efficient second-order nonlinear susceptibility coefficient for GaSe as from 37 to $51 \mathrm{pm} \mathrm{V}^{-1}$ is observed for GaSe doped with heavier In due to improved optical quality ${ }^{19}$. The coefficient was further increased up to $75 \mathrm{pm} \mathrm{V}^{-1}$ by Ag doping ${ }^{19}$. GaSe doped with 0.5 at. $\%$ of Er in charge composition demonstrated a $24 \%$

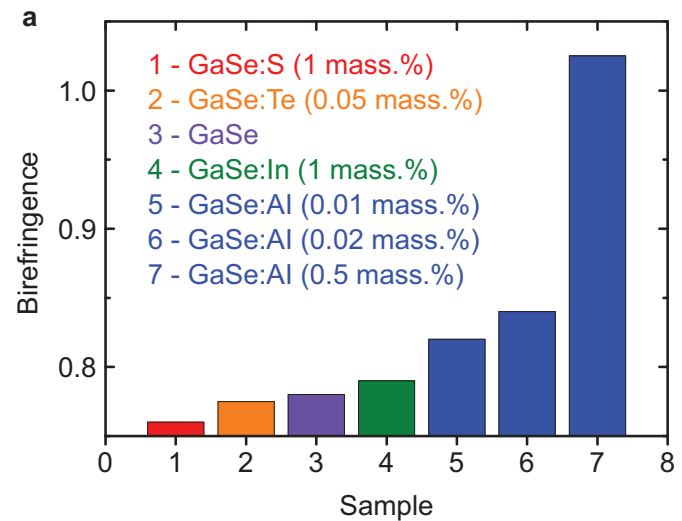

increase in the intrinsic nonlinearity ${ }^{71}$. Bearing in mind the low Er solubility $^{21}$, the increase appears to be due largely to the improved optical quality.

It was established properly that the maximal transparency window $^{42,49,55,61,69}$ and THz range ${ }^{51}$ absorption coefficients for all properly doped crystals grown by the modified method, i.e., with a rotating heat field, are $2-3$ times lower $\left(\leqslant 0.03-0.06 \mathrm{~cm}^{-1}\right)$ than those for crystals grown by the conventional vertical Bridgman method. These data are confirmed by the increased frequency conversion efficiency. Further doping decreases the optical quality, indicating that there exists an optimal doping level. Measurement by the proposed method, i.e., outside of maximal transparency range ${ }^{49}$, allows us to determine the optimal doping concentrations as:2-3 mass.\% of S in $\mathrm{GaSe}^{55,61}$, $0.5-1$ mass. $\%$ of $\operatorname{In}^{69}, 0.07-0.38$ mass. $\%$ of $\mathrm{Te}^{49,61}, 0.01-0.02$ mass. $\%$ of $\mathrm{Al}^{36,42}$, and 0.5 mass. $\%$ of $\mathrm{Er}^{12}$, by charge composition. In all cases, the optimal doping concentration was again confirmed experimentally by direct comparison of frequency conversion efficiency in pure and doped crystals at a fixed pump intensity. Independent of the dopant, optimally doped crystals demonstrated from 1.5, and often from 2.5-3 times larger efficiency than pure GaSe. In spite of the decrease in the intrinsic nonlinearity, S-doped crystals show the highest efficiency is due to a set of modified physical properties that are responsible for the efficiency of frequency conversion processes: improved optical quality and thermal conductivity, decreased nonlinear absorption, varied PM angles, and decreased refractive indices.

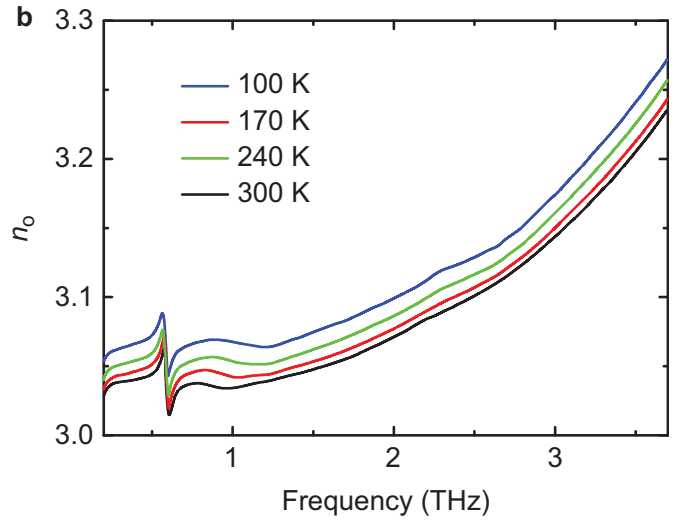

Figure 12 (a) Changes in ordinary wave refractive index versus dopant and its concentration, (b) dispersion properties in GaSe at different temperatures. 

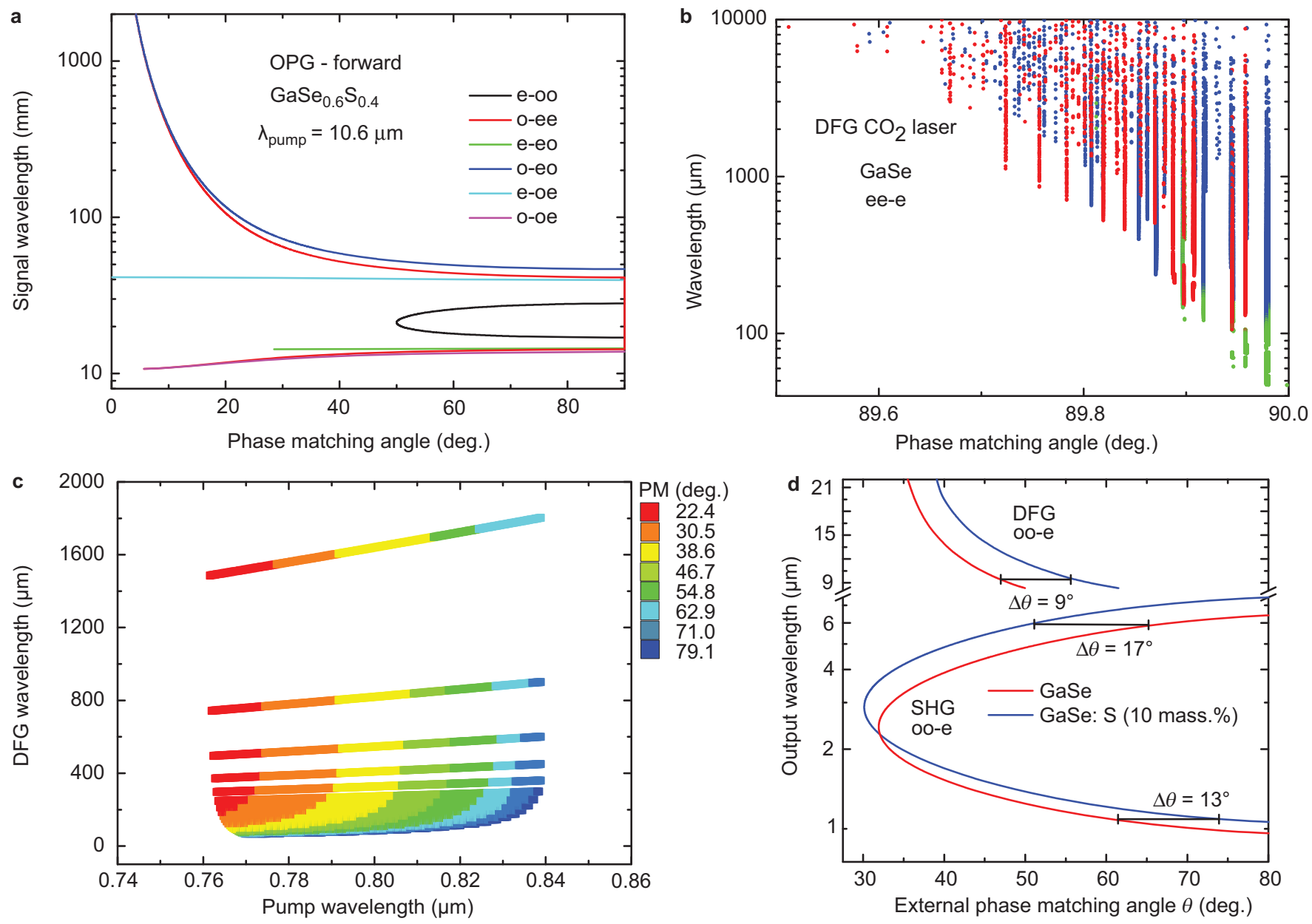

Figure 13 PM curves for (a) forward wave OPG under $\mathrm{CO}_{2}$ laser pump, (b) DFG of two frequency $\mathrm{CO}_{2}$ laser, (c) DFG of two narrow bandwidth frequency tunable Ti:Sapphire lasers operating within from $785 \mathrm{~nm}$ to $815 \mathrm{~nm}$, and (d) SHG and DFG of the same Ti:Sapphire lasers.

This result is well confirmed quantitatively by other groups of researchers $^{58,60}$.

\section{OPTICAL DAMAGE THRESHOLD}

Figure 14 illustrates the advantage of S-doped GaSe with respect to the damage threshold under pumping by an ultrashort pulse Ti:Sapphire laser system (Coherent) consisting of an Nd:YLF laser Verdi-5 V supplied with a BBO SHG that pumps a master Ti:Sapphire laser Mira 900-B. Approximately 100 fs (full width at half maximum (FWHM)) master laser pulses were applied to pump a Ti:Sapphire optical parametric amplifier (OPA) Legend Elite operating at $800 \mathrm{~nm}$. In turn, the frequency doubled output of the OPA was used to pump in parallel two tunable Ti:Sapphire OPG TOPAS-C (Coherent) emitting from 60 to $90 \mathrm{fs}$ (FWHM) pulses, depending on the output wavelengths, at a repetition rate of $1 \mathrm{kHz}$. The OPG operation ranges were $1.1-1.6 \mu \mathrm{m}$ (signal band) and 1.6-2.9 $\mu \mathrm{m}$ (idler band).

The transparency decrease to $10 \%$ under increased pump intensity was found to be a reversible process. Moreover, it was established that the visual criterion in the determination of the crystal damage threshold is not consistent because observation of the black matter damage spots on the crystal surfaces does not reduce noticeably either the transparency or the frequency conversion efficiency. The black matter, identified as amorphous selenium and cadmium, appeared due to GaSe dissociation; these materials are transparent at the pump wavelength. Real damage was identified as solidified well-cohesive Ga structures on the crystal facets after higher exposure intensity. There is no reason for such high intensity pumping or long-term exposure to

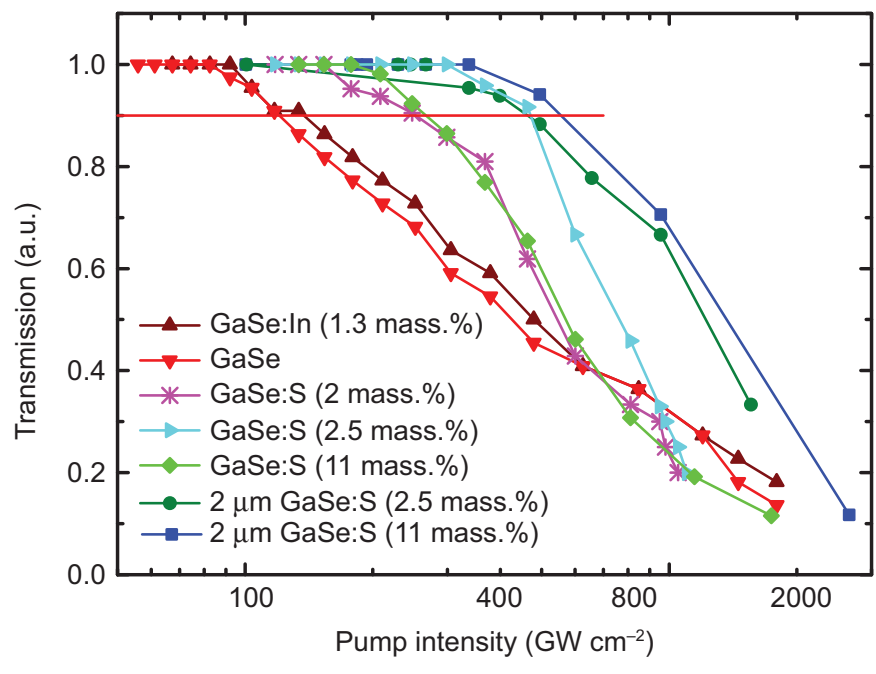

Figure 14 Damage threshold for pure, optimally In- and S-doped GaSe under $0.8 \mu \mathrm{m}$ and $2 \mu \mathrm{m}$ (labeled by "2 $\mu \mathrm{m}$ " before chemical formula) pump by fs Ti:Sapphire OPA. 
lead to real damage because a dramatic decrease in the transparency, and potential frequency conversion efficiency occurs at much lower intensities and shorter exposure times. Therefore, we aim to determine the limit on pump intensity that results in acceptable decrease in the frequency conversion efficiency.

Figure 14 shows that the low solubility of larger sized In atoms substituting for Ga resulted in a small increase in the damage threshold under $0.8 \mu \mathrm{m}$ pumping compared to that of GaSe. Optimally S-doped crystals have a damage threshold 4.5-5 times larger than undoped GaSe. This result is due to very low nonlinear absorption and improved optical quality caused by heavy doping, resulting in a short wave shift of the absorption edge. Figure 14 also shows that, under $2-\mu \mathrm{m}$ pump excitation, the damage threshold is almost the same as for a $0.8-\mu \mathrm{m}$ pump excitation, which confirms the decreased nonlinear absorption for heavily S-doped GaSe. The small difference between them at higher pump intensity can be explained by differences in the beam parameters, higher-order multiphoton absorption and transient transmissions. Moreover, ns pulse pumping causes thermal effects, leading to GaSe dissociation in the crystal bulk at the location of nano or micro defects, eventually resulting in the local slicing off or breakdowns.

Ultimately, optimally doped crystals show up to 15 times greater frequency conversion efficiencies under the limited pump intensity than that of pure GaSe grown by conventional technology, ${ }^{8,75}$. Cascaded processes recently allowed for coverage of the $2.4-8.8 \mu \mathrm{m}$ range by frequency converted emission of a fs Ti:Sapphire laser in doped GaSe crystals with the total photon efficiency of up to $50 \%{ }^{84}$. Nevertheless, negative effects of different dopants on the frequency conversion efficiency have also been observed ${ }^{85}$.

\section{CONCLUSION AND PERSPECTIVES}

Modified synthesis and vertical Bridgman growth technology with heat field rotation in the melt was designed. $\varepsilon$-polytype, $\overline{6} \mathrm{~m} 2$ point group symmetry, GaSe crystals lightly and heavily doped with isovalent single chemical elements $\mathrm{Al}, \mathrm{S}, \mathrm{In}, \mathrm{Te}, \mathrm{Er}, \mathrm{S}$, and $\mathrm{Ag}$ are grown using the modified technology. Crystals are grown also from the melts of GaSe and isovalent $\mathrm{Al}$, which do not form a binary compound, isovalent $\mathrm{Er}$, which does not form isostructural binary compound, as well as non-isovalent element Ag. Moreover, single- and double (In and $\mathrm{Al}$, and $\mathrm{S}$ and $\mathrm{Al}$ )-element doped $\mathrm{GaSe}$ crystals are grown from the melt of GaSe and the isostructural binary compounds GaS, InS, InS or other $(\overline{4} 2 \mathrm{~m})$ point group symmetry ternary compounds, $\mathrm{AgGaSe}_{2}$ and $\mathrm{AgGaS}_{2}$.

We verified that independent of the growth technology, heavily In- and S-doped crystals are ternary solid solution crystals $\mathrm{Ga}_{1-x} \mathrm{In}_{x} \mathrm{Se}$ and $\mathrm{GaSe}_{1-x} \mathrm{~S}_{x}$. Crystals grown from the melt with $\mathrm{Al}$, $\mathrm{Er}$, or $\mathrm{Ag}$ are respectively identified as light $\mathrm{Al}, \mathrm{Er}$, or $\mathrm{Ag}$ doped GaSe due to their low solubility (below 0.1). Crystals grown from the melt of GaSe and InS are ternary solid solution crystals $\mathrm{Ga}_{1-x} \mathrm{In}_{\mathrm{x}} \mathrm{Se}_{1-y} \mathrm{~S}_{y}$. Double-element doped GaSe crystals are ternary solid solution crystals $\mathrm{Ga}_{1-x} \mathrm{In}_{x} \mathrm{Se}$ and $\mathrm{GaSe}_{1-x} \mathrm{~S}_{x}$ doped with Al.

The modification of physical properties strongly depends on the chosen dopant and its concentration. Maximal magnitudes of mixing ratios $x$ and $y$ depend on the atomic size of the dopants: the closer in size to substituted atom, the larger the mixing ratio. S-doping allowed us to achieve a maximal mixing ratio of $x=0.44$, which lead to the largest changes in optical properties and the greatest strengthening of the GaSe structure.

$\mathrm{Al}$, which has a small atomic size, appears as to be an extremely efficient free electron donor that compensates for $p$-type GaSe conductivity; it reduces the free carrier density by $5-7$ orders of magnitude and most efficiently strengthens the lattice structure, among all other dopants. Moreover, Al-doping allows for control of the plasma input to the dielectric response in the $\mathrm{THz}$ range, which occurs without impact on the dielectric properties within the maximal transparency window. Double-element doping results in an additive effect relative to single element doping.

The most attractive is doping with $\mathrm{S}$ and $\mathrm{Al}$, which allows for control of the optical properties and lattice strengthening within wide ranges. Strengthened crystals allowed us to manufacture samples cut and polished in an arbitrary direction. In turn, the cutting and polishing the strengthened crystals allowed us to study for the first time the optical properties of GaSe crystals for e-polarized light waves over the entire transparency range.

Absorption coefficients for crystals grown by the modified technology are 2-3 times lower, across the entire transparency range, compared to that of doped GaSe crystals grown by conventional technology. The absorption coefficient decreased to $0.03-0.06 \mathrm{~cm}^{-1}$ in the mid-IR and $1 \mathrm{~cm}^{-1}$ in the $\mathrm{THz}$ range for optimally doped crystals. Optimal doping concentrations were established as 2-3 mass.\% of $\mathrm{S}$ in $\mathrm{GaSe}^{55,61}, 0.5-1$ mass.\% of $\mathrm{In}^{69}, 0.07-0.38$ mass.\% of $\mathrm{Te}^{49,61}, 0.01-0.02$ mass $\%$ of $\mathrm{Al}^{36,42}$, and 0.5 mass. $\%$ of $\mathrm{Er}^{12}$, by charge composition. Optimally doped crystals also have 2-3 times lower absorption coefficients compared to that for undoped GaSe; down to $0.2 \mathrm{~cm}^{-1}$ in the $\mathrm{THz}$ range.

No increase in the intrinsic nonlinearity for doped crystals was found. The intrinsic nonlinearity for S-doped GaSe is reduced in proportion to the S-content. Nevertheless, all optimally doped crystals demonstrate 1.5-3 times higher frequency conversion efficiency compared to that for GaSe at a fixed pump intensity, due to the improved optical properties. Notably, that S-doped crystals show 3 times higher efficiency than that of pure GaSe, due to the full set of modified physical properties. Moreover, optimally doped crystals show an increased damage threshold over that for GaSe. Here again, a maximal increase in the damage threshold, from 4.5 to 5 times, is demonstrated by optimally S-doped crystals, due to the shift in the transparency range toward the short wave and the related decrease in nonlinear absorption. Thus, for maximal pumping intensity, S-doped crystals show an improvement of up to 15 times in mid-IR frequency conversion efficiency.

Further improvement in the frequency conversion efficiency is possible by exploiting new data on the physical properties developed for grown crystals. In particular, e-wave absorption coefficients for the $\mathrm{THz}$ range are a few times lower in comparison with o-wave coefficients, making e-wave generation of THz waves preferable. Established anisotropic properties for absorption and dispersions allow for adequate selection of the best type of the three frequency interactions (even including the uncommon ee-e or oo-o type) and the optimization of PM. Additional opportunities in PM optimization arise from the possibility of independent engineering of $\mathrm{THz}$ dispersions by the control of free charge carriers, through doping with $\mathrm{Al}$ or other elements and through temperature control. A detailed comparison of forward, backward, and vector interactions is a promising method of improving the frequency conversion efficiency. Outstanding physical properties permit numerous other applications of doped GaSe crystals, such as in the design of dipole type emitters and detectors, electro-optic detectors, polarization optics, nuclear particle detectors, etc. As a result, the applications of doped GaSe crystals are rapidly expanding.

\section{ACKNOWLEDGEMENTS}

This work is supported in part by the Visiting Professor Program of State Key Laboratory of Laser Interaction with Matter of Changchun Institute of Optics, 
Fine Mechanics and Physics CAS, Changchun, China, the Open Fund by State Key Laboratory of Laser Interaction with Matter (No. SKLLIM1012), the RNF (Project No. 15-19-10021, physical properties study), the Tomsk State University (8.1.51.2015), Tomsk Regional Common Use Center, with the support of the Russian Ministry of Education and Science (Agreement No.14.594.21.0001, code RFMEFI59414X0001, spectroscopic study), and the Presidium SB RAS, Project VIII.80.2.4 (optical properties study in THz range). The authors also thank Shabalina A.V. for help in preparing the manuscript.

1 Klemm W, Vogel HUV. Uber die chalkogenide von gallium und indium. Zeitschrift für Anorganische Chemie 1934; 219: 45-64.

2 Andreev YM, Apollonov VV, Shakir YA, Verozubova GA, Gribenyukov Al. Submillimeter waves generation with $\mathrm{ZnGeP}_{2}$ crystals. J Korean Phys Soc 1998; 33: 356-361.

3 Chen CW, Tang TT, Lin SH, Huang JY, Chang CS et al. Optical properties and potential applications of $\varepsilon$-GaSe at terahertz frequencies. J Opt Soc Am B 2009; 26: A58-A65.

4 Nazarov MM, Shkurinov AP, Angeluts AA, Sapozhnikov DA. On the choice of nonlinear optical and semiconductor converters of femtosecond laser into terahertz range. Radiophys Quant Electron 2009; 52: 536-545.

5 Dmitriev VG, Gurzadyan GG, Nikogosyan DN. Handbook for Nonlinear Optical Crystals, Springer Series in Optical Sciences, Vol. 64, 3rd ed. Berlin: Springer, 1999.

6 Tochitsky SY, Sung CE, Trubnick SE, Joshi C, Vodopyanov KL. High-power tunable, 0.5-3 THz radiation source based on nonlinear difference frequency mixing of $\mathrm{CO}_{2}$ laser lines. J Opt Soc Am B 2007; 24: 2509-2516.

7 Vodopyanov KL, Mirov SB, Voevodin VG, Schunemann PG. Two-photon absorption in GaSe and CdGeAs 2. Opt Comm 1998; 155: 47-50.

8 Guo J, Li DJ, Xie JJ, Zhang LM, Feng ZS et al. Limit pump intensity of Ti: sapphire laser systems for $\mathrm{GaSe}_{1-\mathrm{x}} \mathrm{S}_{\mathrm{x}}$. Laser Phys Lett 2014; 11: 055401.

9 Fernelius NC. Properties of gallium selenide single crystal. Prog Cryst Growth Charact 1994; 28: 275-353.

10 Abdullaev GB, Kulevskii LA, Prokhorov AM, Savel'ev AD, Salaev E Yu et al. GaSe, a new effective material for nonlinear optics. JETP Letters 1972; 16: 90-92.

11 Kador L, Haarer D, Allakhverdiev KR, Salaev EY. Phase-matched second-harmonic generation at $789.5 \mathrm{~nm}$ in a GaSe crystal. Appl Phys Lett 1996; 69: 731-733.

12 Shi W, Ding YJ. A monochromatic and high-power terahertz source tunable in the ranges of 2.7-38.4 and 58.2-3540 $\mu \mathrm{m}$ for variety of potential applications. App Phys Lett 2004; 84: 1635-1637.

13 Tochitsky SY, Sung C, Trubnick SE, Joshi C, Vodopyanov KL. High-power tunable, 0.5$3 \mathrm{THz}$ radiation source based on nonlinear difference frequency mixing of $\mathrm{CO}_{2}$ laser lines. J Opt Soc Am B 2007; 24: 2509-2516.

14 Ding YJ, Shi W. Widely tunable monochromatic THz sources based on phase-matched difference-frequency generation in nonlinear-optical crystals: a novel approach. Laser Phys 2006; 16: 562-570.

15 Wilke I, Sengupta S. Pulse generation and detection-optical rectification and electrooptic sampling. In: Dexeimer UL, editor. Terahertz Spectroscopy: Principles and Applications. Boca Raton: CRC Press; 2008, pp. 41-72.

16 Kokh KA, Andreev YM, Svetlichnyi VA, Lanskii GV, Kokh AE. Growth of GaSe and GaS single crystals. Cryst Res Technol 2011; 46: 327-330.

17 Andreev YM, Kokh KA, Lanskii GV, Morozov AN. Structural characterization of pure and doped GaSe by nonlinear optical method. J Cryst Growth 2011; 318: 1164 1166.

18 Shi W, Leigh M, Zong J, Jiang S. Single-frequency terahertz source pumped by Qswitched fiber lasers based on difference-frequency generation in GaSe crystal. Opt Lett 2007; 32: 949-951.

19 Suhre DR, Singh NB, Balakrishna V, Fernelius NC, Hopkins FK. Improved crystal quality and harmonic generation in GaSe doped with indium. Opt Lett 1997; 22 : 775-777.

20 Rak Z, Mahanti SD, Mandal KC, Fernelius NC. Electronic structure of substitutional defects and vacancies in GaSe. J Phys Chem Solids 2009; 70: 344-355.

21 Feng ZS, Guo J, Xie JJ, Zhang LM, Gao JY et al. GaSe: $\mathrm{Er}^{3+}$ crystals for SHG in the infrared spectral range. Opt Commu 2014; 318: 205-211.

22 Rizzo A, de Blasi C, Catalano M, Cavaliere P. Dislocations in A"I B IV crystals. Phys Stat Sol A 1988; 105: 101-112.

23 Kasuya A, Sasaki Y, Hashimoto S, Nishina Y, Iwasaki H. Stacking fault density and splitting of exciton states in $\varepsilon-G a S e$. Sol State Comm 1985; 55: 63-66.

24 Allakhverdiev KR, Guliev RI, Salaev EY, Smirnov VV. Investigation of linear and nonlinear optical properties of $\mathrm{GaSe}_{x} \mathrm{Se}_{1-x}$ crystals. Soviet J Quantum Electron 1982; 12: 947-948.

25 Singh NB, Suhre DR, Balakrishna V, Marable M, Meyer R et al. Far-infrared conversion materials: gallium selenide for-infrared conversion applications. Prog Cryst Growth Charact Mater 1998; 37: 47-102.

26 Singh NB, Suhre DR, Rosch W, Meyer R, Marable M et al. Modified GaSe crystals for mid-IR applications. J Cryst Growth 1999; 198: 588-592.

27 Ding YJ. High-power tunable terahertz sources based on parametric frequency conversion process and applications. IEEE J Sel Top Quant Elect2007; 13: 705-720.

28 Ding YJ. Progress in terahertz sources based on difference-frequency generation [Invited]. J Opt Soc Am B 2014; 31: 2696-2710.
29 Gouskov A, Camassel J, Gouskov L. Growth and characterization of III-VI layered crystals like GaSe, GaTe, InSe, GaSe $e_{1-x} \mathrm{Te}_{\mathrm{x}}$ and $\mathrm{Ga}_{\mathrm{x}} \mathrm{In}_{1-\mathrm{x}} \mathrm{Se}$. Prog Cryst Growth Charact 1982; 5: 323-413.

30 Vohl P. Synthesis and crystal growth of $\mathrm{CdGeP}_{2}$. J Electron Mater 1979; 8: 517-528.

31 Singh NB, Narayanan R, Zhao AX, Balakrishna V, Hopkins RH et al. Bridgman growth of GaSe crystals for nonlinear applications. Mat Sci Eng 1997; B49: 243-246.

$32 \mathrm{Ni} \mathrm{Y}$, Wu H, Huang C, Mao M, Wang Z et al. Growth and quality of gallium selenide (GaSe) crystals. J Crystal Growth 2013; 381: 10-14.

33 Kokh KA, Nenashev BG, Kokh AE, Shvedenkov GY. Application of a rotating heat field in Bridgman-Stockbarger crystal growth. J Crystal Growth 2005; 275: E2129E2134.

34 Atuchin VV, Beisel NF, Kokh KA, Kruchinin VN, Korolkov IV. Growth and microstructure of heterogeneous crystal GaSe: InS. Cryst Eng Comm 2013; 15 : 1365-1369.

35 Molloy JF, Naftaly M, Andreev YM, Lanskii GV, Lapin IN et al. Dispersion properties of GaS studied by THz-TDS. Crys Eng Comm 2014; 16: 1995-2000.

36 Guo J, Xie JJ, Zhang LM, Li DJ, Yang GL et al. Characterization of Bridgman grown GaSe: Al crystals. Cryst Eng Comm 2013; 15: 6323-6328.

37 Karabulat M, Blir G, Mamedov GM, Seyhan A, Turan R. Photoluminescence spectra of nitrogen implanted GaSe crystals. J Luminescence 2008; 128: 1551-1555.

38 Pokladok NT, Gryforchak II, Lukiyanets BA, Popovich DI. Structure and physical properties of gallium selenide laser-intercalated with nickel. Phy Sol State 2007; 49: 715-718.

39 Voevodin VG, Voevodina OV, Bereznaya SA, Korotchenko ZV, Morozov AN et al. Goldstein large single crystals of gallium selenide: growing, doping by In and characterization. Opt Mater 2004; 26: 495-499.

40 Howe JM. The Al-Se (aluminum-selenium) system. Bull Alloy Phase Diagrams 1989; 10: 650-652.

41 Fischer P, Hälg W, Hulliger F. Magnetic ordering in HoBi, HoS, ErS and ErSe. Phys B+C 1985; 130: 551-554.

42 Zhang YF, Wang R, Kang ZH, Qu LL, Jiang Y et al. AgGaS ${ }_{2}$ - and Al-doped GaSe crystals for IR applications. Opt Comm 2011; 284: 1677-1681.

43 Feng ZS, Li SM, Izaak TI, Kokh KA, Losev VF et al. Optical properties of nonlinear solid solution crystals GaSe: InSe. Russ Phys J 2013; 56: 5-8. Russian.

44 Xie JJ, Guo J, Zhang LM, Li DJ, Yang GL et al. Optical properties of non-linear crystal grown from the melt GaSe-AgGaSe 2 . Opt Comm 2013; 287: 145-149.

45 Abdinov AS, Allakhverdiev SA, Babaeva RF, Rzaev RM. Electrical conductivity of undoped and rare-earth-doped high-resistivity GaSe crystals. Inorg Mater 2009; 45 : 785-789.

46 Mamedov GM, Karabulut M, Ertrap H, Kodolbas O, Oktu $\mathrm{O}$ et al. Exciton photoluminescence, photoconductivity and absorption in $\mathrm{GaSe}_{0.9} \mathrm{Te}_{0.1}$ alloy crystals. J Luminescence 2009; 129: 226-230.

47 Huang J, Ji GJ, Shen T, Andreev YM, Shaiduko AV et al. Influence of composition ratio variation on optical frequency conversion in mixed crystals. I. Gradual variation of composition ratio. J Opt Soc Am B 2007; 24: 2443-2453.

48 Huang J, Gao W, Shen T, Mao BL, Andreev YM et al. Influence of composition ratio variations on optical frequency conversion in mixed crystals. II. Random variation of composition ratio. J Opt Soc Am B 2007; 24: 3081-3090.

49 Ku SA, Chu WC, Luo CW, Andreev Y, Lanskii G et al. Optimal Te-doping in GaSe for non-linear applications. Opt Express 2012; 20: 5029-5037.

50 Guo J, Li DJ, Xie JJ, Zhang LM, Kokh $\mathrm{K}$ et al. Characterization of optical quality of GaSe: Al crystals by exciton absorption peak parameters. J Mater Science: Mater Electron 2014: 25: 1757-1760.

51 Molloy JF, Naftaly M, Andreev Y, Kokh K, Lanskii G. Absorption anisotropy in sulfur doped gallium selenide crystals studied by THz-TDS. Opt Mater Express 2014; 4: 2451-2459.

52 Molloy JF, Naftaly M, Andreev Y, Kokh KA, Lanskii GV et al. Solid solution GaSe $e_{1-x} S_{x}$ crystals for THz applications. International Conference on Infrared, Millimeter, and Terahertz Waves (IRMMW-THz), Tucson, AZ, , USA, 2014.

53 Das S, Ghosh C, Voevodina OG, Andreev YM, Sarkisov SY. Modified GaSe crystal as a parametric frequency converter. Appl Phys B 2006; 82: 43-46.

54 Andreev YM, Atuchin VV, Lanskii GV, Morozov AN, Pokrovsky LD et al. Growth, real structure and applications of $\mathrm{GaSe}_{1-x} \mathrm{~S}_{\mathrm{x}}$ crystals. Mater Science Eng B 2006; 128 : 205-210.

55 Zhang HZ, Kang ZH, Jiang Y, Gao JY, Wu FG et al. SHG phase matching in GaSe and mixed $\mathrm{GaSe}_{1-x} \mathrm{~S}_{\mathrm{x}}, \mathrm{x} \leqslant 0.412$, crystals at room temperature. Opt Express 2008; 16: 9951-9957.

56 Cuculescu E, Evtodiev I, Caraman I. The anisotropy of the optical properties of ternary semiconductors formed by elements of III and VI groups. Phys Stat Sol B 2009; 6: 1207-1212.

57 Luo ZW, Gu XA, Zhu WC, Tang WC, Andreev Y et al. Optical properties of GaSe: S crystals in terahertz frequency range. Opt Prec Eng 2011; 19: 354-359. Chinese.

58 Petrov V, Panyutin VL, Tyazhev A, Marchev G, Zagumennyi Al et al. GaS ${ }_{0.4} \mathrm{Se}_{0.6}$ : relevant properties and potential for $1064 \mathrm{~nm}$ pumped mid-IR OPOs and OPGs operating above $5 \mu \mathrm{m}$. Laser Phys 2011; 21: 774-781.

59 Miyata K, Marchev G, Tyazhev A, Panyutin V, Petrov V. Picosecond mid-infrared optical parametric amplifier based on the wide-bandgap $\mathrm{GaS}_{0.4} \mathrm{Se}_{0.6}$ pumped by a Nd: YAG laser system at $1064 \mathrm{~nm}$. Opt Lett 2011; 36: 1785-1787.

60 Marchev G, Tyazhev A, Panyutin V, Petrov V, Noack F et al. Some properties of the mixed $\mathrm{GaS}_{0.4} \mathrm{Se}_{0.6}$ nonlinear crystal in comparison to GaSe. Proc SPIE 2011; 7917: $79171 \mathrm{G}$.

61 Feng ZS, Guo J, Kang ZH, Jiang Y, Gao JY et al. Tellurium and sulphur doped GaSe for mid-IR applications. Appl Phys B 2012; 108: 545-552. 
62 Andreev YM, Lanskii GV, Shaiduko AV, Vaitulevich EA, Svetlichnyi VA et al. Optimal doping of GaSe for nonlinear optical applications. Russ Phys J 2014; 57: 12501257.

63 Ku SA, Luo CW, Andreev YM, Lanskii G. Comment on "GaSe $e_{1-x} \mathrm{~S}_{x}$ and $\mathrm{GaSe}_{1-x} \mathrm{Te}_{\mathrm{x}}$ thick crystals for broadband terahertz pulses generation" [Appl. Phys. Lett. 99, 081105 (2011)]. Appl Phys Lett 2012; 100: 136103.

64 Chu WC, Ku SA, Wang HJ, Luo CW, Andreev YM et al. Widely linear and non-phasematched optics-to-THz conversion on GaSe: Te crystals. Opt Lett2012; 37: 945-947.

65 Ku SA, Chu WC, Luo CW, Andreev YM, Lanskii GV et al. Optical properties of Te-doped GaSe crystal. Chinese Optics 2011; 4: 660-666.

66 Evtodiev I, Leontie L, Caraman M, Stamate M, Arama E. Optical properties of p-GaSe single crystals doped with Te. J App/ Phys 2009; 105: 023524.

67 Das S, Ghosh C, Gangopadhyay S, Chatterjee U, Bhar GC. Tunable coherent infrared source from 5-16 $\mu \mathrm{m}$ based on difference-frequency mixing in an indium-doped GaSe crystal. J Opt Soc Am B 2006; 23: 282-288.

68 Saintonge G, Brebner JL. Infrared spectra of $\mathrm{Ga}_{x} \mathrm{In}_{1-x}$ Se. Can J Phys 1984; 62: 730 736.

69 Feng ZS, Kang ZH, Wu FG, Gao JY, Jiang Y et al. SHG in doped GaSe: In crystals. Opt Express 2008; 16: 9978-9985.

70 Rak Z, Mahanti SD, Mandal KC, Fernelius NC. Doping dependence of electronic and mechanical properties of $\mathrm{GaSe}_{1-\mathrm{x}} \mathrm{Te} \mathrm{e}_{\mathrm{x}}$ and $\mathrm{Ga}_{1-\mathrm{x}} \ln \mathrm{n}_{\mathrm{x}} \mathrm{Se}$ from first principles. Phys Rev $B$ 2010; 82: 155203.

71 Hsu YK, Chen CW, Huang JY, Pan CL, Zhang JY et al. Erbium doped GaSe crystal for mid-IR applications. Opt Express 2006; 14: 5484-5491.

72 Xie JJ, Jiang K, Wang CR, Andreev Y, Kokh K et al. Two-element doped nonlinear GaSe crystals. The 3rd Int Symp Laser Interaction Matter (LIMIS' 2014) 2-5. 11. 2014, Nanjing, China; Symp Agenda and Abstracts, 0-05-006: 206.

73 Ku SA, Chu WC, Luo CW, Angeluts AA, Evdokimov MG et al. Optical properties and application of GaSe: AgGaSe 2 crystals. Chinese Optics 2012; 5: 57-63.

74 Zotova IB, DingYJ. Spectral measurements of two-photon absorption coefficients for CdSe and GaSe crystals. Appl Opt 2001; 40: 6654-6658.

75 Feng ZS, Kang ZH, Li XM, Gao JY, Andreev YM et al. Impact of $\mathrm{fs}$ and ns pulses on solid solution crystals $\mathrm{Ga}_{1-x} \mathrm{In}_{\mathrm{x}} \mathrm{Se}$ and $\mathrm{GaSe}_{1-\mathrm{x}} \mathrm{S}_{\mathrm{x}}$. AIP Advances 2014; 4: 037104.
76 Allakhverdiev K, Baykara T, Ellialtioglu S, Hashimzade F, Huseinova D et al. Lattice vibrations of pure and doped GaSe. Mater Res Bull 2006; 41: 751-763.

77 Vodopyanov KL, Kulevskii LA. New dispersion relationships for GaSe in the 0.65-18 $\mu \mathrm{m}$ spectral region. Opt Comm 1995; 118: 375-378.

78 Kato K, Umemura N. Sellmeier equations for GaS and GaSe and their applications to the nonlinear optics in $\mathrm{GaS}_{\mathrm{x}} \mathrm{Se}_{1-\mathrm{x}}$. Opt Lett 2011; 36: 746-747.

79 Edwards DF. Gallium Selenide (GaSe). In: Palik ED, editor. Handbook of Optical Constants of Solids, V. III. London: Academic Press; 1997, pp. 473-487.

80 Zhang LM, Guo J, Li DJ, Xie JJ, Andreev YM et al. Dispersion properties of $\mathrm{GaSe}_{1-x} \mathrm{~S}_{\mathrm{x}}$ in the terahertz range. J App/ Spectr 2011; 77: 850-856.

81 Takaoka E, Kato K. $90^{\circ}$ phase-matched third-harmonic generation of $\mathrm{CO}_{2}$ laser frequencies in $\mathrm{AgGa}_{1-x} \mathrm{In}_{\mathrm{x}} \mathrm{Se}_{2}$. Opt Lett 1999; 24: 902-904.

82 Allakhverdiev K, Fernelius N, Gashimzade F, Goldstein J, Salaev E et al. Anisotropy of optical absorption in GaSe studied by mid infrared spectroscopy. J App/ Phys 2003; 93: 3336-3339.

83 Chao ZW, An YH, Andreev YM, Grechin SG, Lankii GV et al. Simulation of thermo-optic coupling in the thermally anisotropic crystal GaSe for second harmonic generation. Laser Phys Lett 2014; 11: 075402.

84 Lubenko DM, Losev VF, Andreev YM, Lanskii GV, Svetlichnyi VA. Generating femtosecond pulses in the mid-IR and $\mathrm{THz}$ ranges in $\mathrm{GaSe}_{1-\mathrm{x}} \mathrm{Te}_{\mathrm{x}}$ crystals. Bull Russ Acad Sci Phys 2015; 79: 238-241.

85 Telminov AE, Sitnikov AG, Panchenko AN, Genin DE, Sarkisov SY et al. Dispersion equations with accounting of phonon spectra transformation. Theses of 10 th Conf. on Modification of Materials with Particle Beams and Plasma Flows, Tomsk, Russia, 2010, 323-324.

(c) (i) $(-)$ This work is licensed under a Creative Commons Attribution-NonCommercialcc. ${ }_{\mathrm{BY}} \mathrm{NC}$ ND NoDerivs 4.0 Unported License. The images or other third party material in this article are included in the article's Creative Commons license, unless indicated otherwise in the credit line; if the material is not included under the Creative Commons license, users will need to obtain permission from the license holder to reproduce the material. To view a copy of this license, visit http://creativecommons.org/licenses/by-nc-nd/4.0/ 